\title{
Weakening of Northwest Pacific Anticyclone Anomalies during Post-EI Niño Summers under Global Warming $\mathscr{O}$
}

\author{
WENPING JIANG \\ State Key Laboratory of Numerical Modeling for Atmospheric Sciences and Geophysical Fluid Dynamics, Institute of \\ Atmospheric Physics, Chinese Academy of Sciences, and University of Chinese Academy of Sciences, Beijing, China

\section{GANG HUANG} \\ State Key Laboratory of Numerical Modeling for Atmospheric Sciences and Geophysical Fluid Dynamics, \\ Institute of Atmospheric Physics, Chinese Academy of Sciences, and University of Chinese Academy of Sciences, \\ Beijing, and Laboratory for Regional Oceanography and Numerical Modeling, Qingdao National Laboratory for \\ Marine Science and Technology, Qingdao, China

\section{Ping Huang AND Kaiming Hu} \\ State Key Laboratory of Numerical Modeling for Atmospheric Sciences and Geophysical Fluid Dynamics, \\ and Center for Monsoon System Research, Institute of Atmospheric Physics, Chinese Academy of \\ Sciences, Beijing, China
}

(Manuscript received 15 September 2017, in final form 31 January 2018)

\begin{abstract}
The northwest Pacific anticyclone (NWPAC) anomalies during post-El Niño summers are a key predictor of the summer climate in East Asia and the northwestern Pacific (NWP). Understanding how this will change under global warming is crucial to project the changes in the variability of the northwest Pacific summer monsoon. Outputs from 18 selected coupled models from phase 5 of the Coupled Model Intercomparison Project show that the anomalous NWPAC response to El Niño will likely be weakened under global warming, which is attributed to the decreased zonal contrast between the tropical Indian Ocean (TIO) warming and the NWP cooling during post-El Niño summers. Under global warming, the NWPAC anomalies during the El Niño mature winter are weakened because of decreased atmospheric circulation in response to El Niño-Southern Oscillation (ENSO), which leads to the weakening of local air-sea interaction and then decreases the cold NWP SST anomalies. Furthermore, the decreased surface heat flux anomalies, the weakened anticyclone anomalies over the southeastern Indian Ocean, and the slackened anomalous easterlies over the north Indian Ocean weaken the warm TIO SST anomalies. However, the strengthened tropospheric temperature anomalies could enhance the anomalous TIO warming. Although the changes in TIO SST anomalies are indistinctive, the weakening of the SST anomaly gradient between the TIO and the NWP is robust to weaken the NWPAC anomalies during post-El Niño summers. Moreover, the positive feedback between the TIO-NWP SST anomalies and the NWPAC anomalies will enhance the weakening of NWPAC under global warming.
\end{abstract}

\section{Introduction}

The northwest Pacific summer monsoon (NWPSM) is one of the important subcomponents of the Asian summer monsoon. The NWPSM displays pronounced

Supplemental information related to this paper is available at the Journals Online website: https://doi.org/10.1175/JCLI-D-17-0613.s1.

Corresponding author: Dr. Ping Huang, huangping@mail.iap. ac.cn interannual variability and has considerable socioeconomic impacts on the summer climate in South and East Asia (Kosaka et al. 2013; Wang et al. 2013; Oh and Ha 2016; Ha et al. 2017). The summer convective anomalies over the northwestern Pacific (NWP) are highly dependent on El Niño-Southern Oscillation (ENSO) activity (Huang and Wu 1989; Chang et al. 2000; Chou et al. 2009; Lin and Lu 2009; Chen and Zhou 2014). An anomalous northwest Pacific anticyclone (NWPAC) emerges during the El Niño mature winter and persists in the El Niño decaying spring and summer, which is a 
key bridge linking El Niño to the summer climate over the NWP and East Asia (Zhang et al. 1999; Lau and Nath 2000; Wang et al. 2000; Zhang and Sumi 2002; Chou et al. 2003; Wang et al. 2003; Hu et al. 2014).

Understanding how the NWPSM response to El Niño during post-El Niño summers will change under global warming is important for projecting the NWPSM variability in the future. Previous studies demonstrate considerable disagreement on the influence of global warming on the ENSO-NWPSM teleconnection. Song and Zhou (2015) suggested that the effects of global warming on modulating the relationship between ENSO and the East Asia summer climate are negligible. Chowdary et al. (2012) concluded that the strengthened response of summer climate in East Asia to ENSO after the mid-1970s is not entirely due to global warming, but also reflects internal variability. Other studies have suggested that the intensity of the NWPSM in response to El Niño is mainly modified by internal variability, such as the variation in ENSO amplitude and periodicity (Wang et al. 2008), the variation in the tropical Indian Ocean (TIO) in response to ENSO (Huang et al. 2010; Xie et al. 2010b), and the Pacific decadal oscillation (Feng et al. 2014; Song and Zhou 2015). However, some studies have argued that the TIO in response to ENSO is enhanced under global warming (Zheng et al. 2011; Hu et al. 2014), which is conducive to the strengthening of the response of the NWPSM to El Niño. Chen et al. (2016) suggested that the NWPAC in response to a short decaying El Niño will be intensified in the future. Therefore, the role played by global warming in influencing the NWPSM in response to El Niño in the future is unclear.

Recent studies have suggested, using the coupled atmosphere-ocean general circulation models (CGCMs) participating in phase 5 of the Coupled Model Intercomparison Project (CMIP5), that certain robust changes in the ENSO-induced climate anomalies can be expected; for example, the intensified and eastward-shifted spatial pattern of the ENSO-induced tropical rainfall anomalies (Power et al. 2013; Cai et al. 2014; Huang and Xie 2015; Huang 2016) and the eastward shift of the ENSO-induced Pacific-North American pattern (Kug et al. 2010; Zhou et al. 2014; Bonfils et al. 2015). All of these robust changes in the ENSO-induced anomalies are related to the anomalies during the mature phases of ENSO. The effects of ENSO on the NWPSM may be prolonged during postENSO summers by a series of complex air-sea coupled processes, and the response to global warming of the ENSO-NWPSM teleconnection has not been systematically investigated.

Extensive studies have been conducted to investigate the mechanisms of development of the NWPAC during
post-El Niño summers. One factor maintaining the NWPAC anomalies is the El Niño-induced cooling in the NWP. During the El Niño mature winter and the following spring, the remote forcing from the equatorial central-eastern Pacific and local air-sea interaction maintain the NWPAC anomalies (Wu et al. 2017). Rossby wave cyclonic anomalies triggered by positive rainfall anomalies over the equatorial central-eastern Pacific deliver dry and low moist enthalpy air into the NWP, developing the NWPAC by suppressing local convection (Wu et al. 2017). Moreover, the northeasterly anomalies to the southeastern flank of the NWPAC anomalies enhance the mean northeast trades and cool the in situ SST by enhancing the upward surface latent heat flux. In turn, the diabatic cold SST anomalies in the NWP maintain the NWPAC anomalies to its west by triggering a cold atmospheric Rossby wave (Wang et al. 2000). The positive thermodynamic air-sea feedback contributes to the maintenance of the NWPAC anomalies until the following spring and early summer $(\mathrm{Wu}$ et al. 2010; Wang et al. 2013; Xiang et al. 2013; Xie et al. 2016).

In addition, El Niño may induce a basinwide warming in the TIO with an approximately 3-month lag, which can also prolong the El Niño effect during post-El Niño summers. The TIO warming is caused by the increase in El Niño-induced surface heat flux anomalies (Klein et al. 1999; Lau and Nath 2003), the increased tropical tropospheric temperature (hereinafter the TT mechanism) (Chiang and Sobel 2002; Chiang and Lintner 2005), ocean dynamic processes (Huang and Kinter 2002; Xie et al. 2002), and an antisymmetric pattern of atmospheric circulation (Du et al. 2009). The El Niñoinduced TIO warming can strengthen the NWPAC anomalies through forcing a Matsuno-Gill pattern (Matsuno 1966; Gill 1980) in the tropospheric temperature. A Kelvin wave propagates into the tropical western Pacific and induces an anomalous NWPAC through Ekman divergence and suppressed convection (Yang et al. 2007; Xie et al. 2009; Yang et al. 2010). Furthermore, the easterly wind anomalies on the southern flank of the NWPAC can weaken the westerly monsoon over the northern Indian Ocean (NIO) and contribute to the warming there (Xie et al. 2016). This implies that the Indo-western Pacific SST anomalies and the NWPAC are a positive feedback system during post-El Niño summers (Kosaka et al. 2013; Wang et al. 2013; Xie et al. 2016). Recent studies have suggested that the nonlinear interactions of ENSO and the western Pacific warm pool annual cycle may contribute to the development of the NWPAC (Stuecker et al. 2015, 2016). However, the coupled mode of the Indo-western Pacific cross-basin interaction plays a crucial role in 
TABLE 1. Details of the 30 CMIP5 models. The 12 unselected models are denoted by an asterisk. (See http://cmip-pcmdi.llnl.gov/cmip5/ availability.html for more information; expansions of acronyms are available online at http://www.ametsoc.org/PubsAcronymList.)

\begin{tabular}{|c|c|c|}
\hline Model & Institution, country & $\begin{array}{l}\text { Atmospheric gridpoint resolution } \\
\quad(\text { lon } \times \text { lat, vertical layers })\end{array}$ \\
\hline ACCESS1.0* & $\begin{array}{l}\text { Commonwealth Scientific and Industrial Research Organisation (CSIRO) } \\
\text { and Bureau of Meteorology (BoM), Australia }\end{array}$ & $192 \times 144$, L38 \\
\hline BCC_CSM1.1* & Beijing Climate Center, China Meteorological Administration, China & $128 \times 64, \mathrm{~L} 26$ \\
\hline BCC_CSM1.1(m) & & $320 \times 160$, L26 \\
\hline BNU-ESM & $\begin{array}{l}\text { College of Global Change and Earth System Science, Beijing Normal } \\
\text { University, China }\end{array}$ & $128 \times 64, \mathrm{~L} 26$ \\
\hline CanESM2* & Canadian Centre for Climate Modelling and Analysis, Canada & $128 \times 64, \mathrm{~L} 35$ \\
\hline CCSM4 & National Center for Atmospheric Research, United States & $288 \times 192, \mathrm{~L} 26$ \\
\hline CESM1(CAM5)* & Community Earth System Model Contributors, United States & $288 \times 192, \mathrm{~L} 30$ \\
\hline CMCC-CM* & Centro Euro-Mediterraneo per I Cambiamenti Climatici, Italy & $480 \times 240, \mathrm{~L} 31$ \\
\hline CMCC-CMS* & & $192 \times 96$, L95 \\
\hline CNRM-CM5 & $\begin{array}{l}\text { Centre National de Recherches Météorologiques and Centre Européen de } \\
\text { Recherche et Formation Avancée en Calcul Scientifique, France }\end{array}$ & $256 \times 128, \mathrm{~L} 31$ \\
\hline CSIRO Mk3.6.0* & Queensland Climate Change Centre of Excellence and CSIRO, Australia & $192 \times 96$, L18 \\
\hline FGOALS-g2 & $\begin{array}{l}\text { LASG, Institute of Atmospheric Physics, Chinese Academy of Sciences and } \\
\text { Center for Earth System Science (CESS), Tsinghua University, China }\end{array}$ & $128 \times 60, \mathrm{~L} 26$ \\
\hline FGOALS-s2 & LASG, Institute of Atmospheric Physics, China & $128 \times 108, \mathrm{~L} 26$ \\
\hline FIO-ESM & $\begin{array}{l}\text { First Institute of Oceanography (FIO), State Oceanic Administration } \\
\text { (SOA), China }\end{array}$ & $128 \times 64, \mathrm{~L} 26$ \\
\hline GFDL CM3 & NOAA/Geophysical Fluid Dynamics Laboratory, United States & $144 \times 90, \mathrm{~L} 48$ \\
\hline GFDL-ESM2G & & $144 \times 90, \mathrm{~L} 24$ \\
\hline GFDL-ESM2M & & $144 \times 90, \mathrm{~L} 24$ \\
\hline GISS-E2-H* & NASA Goddard Institute for Space Studies, United States & $144 \times 90, \mathrm{~L} 40$ \\
\hline \multicolumn{3}{|c|}{ 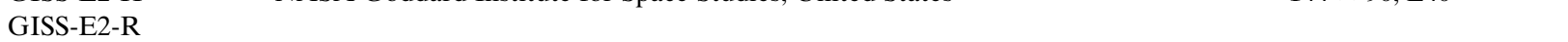 } \\
\hline INM-CM4.0* & Institute of Numerical Mathematics, Russia & $180 \times 120, \mathrm{~L} 21$ \\
\hline IPSL-CM5A-LR & L'Institut Pierre-Simon Laplace, France & $96 \times 95$, L39 \\
\hline IPSL-CM5A-MR* & & $144 \times 143$, L39 \\
\hline IPSL-CM5B-LR & & $96 \times 95$, L39 \\
\hline MIROC5 & University of Tokyo, National Institute for Environmental Studies, and & $256 \times 128, \mathrm{~L} 40$ \\
\hline MIROC-ESM & Japan Agency for Marine-Earth Science and Technology, Japan & $128 \times 64, \mathrm{~L} 80$ \\
\hline MPI-ESM-LR* & Max Planck Institute for Meteorology, Germany & $192 \times 96, \mathrm{~L} 47$ \\
\hline MPI-ESM-MR* & & $192 \times 96$, L95 \\
\hline MRI-CGCM3 & Meteorological Research Institute, Japan & $320 \times 160, \mathrm{~L} 48$ \\
\hline NorESM1-M & Norwegian Climate Centre, Norway & $144 \times 96$, L26 \\
\hline NorESM1-ME & & \\
\hline
\end{tabular}

maintaining the NWPAC during post-El Niño summers (Xie and Zhou 2017).

In the present work, we study the changes in the response of the NWPAC to El Niño during post-El Niño summers under global warming. We select 18 models with high-skill simulation performance from 30 CMIP5 CGCMs to reduce the influence of the model biases. The change under global warming is displayed by the differences between the representative concentration pathway 8.5 (RCP8.5) run and the historical run. We find that the NWPAC response to El Niño will weaken under global warming, and this weakening can mainly be attributed to the decreased zonal contrast between the TIO warming and NWP cooling in the future.

The rest of the paper is organized as follows: Section 2 is a brief description of the observations and model datasets, methods, and model selection criteria. Section 3 presents the main results, including the role of global warming in modulating the response intensity of the NWPSM to ENSO, and the corresponding physical mechanisms. A summary and discussion are presented in section 4.

\section{Models, observational datasets, and methods}

\section{a. Datasets}

The outputs of 30 CMIP5 coupled models (listed in Table 1 with brief descriptions) are used in this study (Taylor et al. 2012; https://esgf-node.llnl.gov/search/ cmip5/). Only one member (realization r1i1p1) run of each model is analyzed. The historical run from 1971 to 2000 is adopted as a baseline of current climate, whereas the RCP8.5 run from 2011 to 2100 is considered as a 
projection of future climate. We use the monthly mean variables, including SST, sea level pressure (SLP), wind, air temperature, shortwave (SW) and longwave (LW) radiation, latent heat flux (LHF), and sensible heat flux (SHF) at the sea surface. All the model datasets are interpolated onto the same $2.5^{\circ} \times 2.5^{\circ}$ grid before analysis.

The reanalysis datasets for the period of 1971-2000 are used to select 18 high-skill models, which display a realistic response of NWPSM to El Niño during post-El Niño summers. The observed SST used in this study is from the monthly mean Extended Reconstruction of Historical Sea Surface Temperature dataset, version 3 (Smith et al. 2008), which has a horizontal resolution of $2^{\circ} \times 2^{\circ}$ (available online at https://www.esrl.noaa.gov/ $\mathrm{psd} /$ data/gridded/data.noaa.ersst.html). For atmospheric circulation data, we use the National Centers for Environmental Prediction (NCEP)-National Center for Atmospheric Research (NCAR) reanalysis $850-\mathrm{hPa}$ wind datasets (Kalnay et al. 1996; available online at https:// www.esrl.noaa.gov/psd/data/gridded/data.ncep.reanalysis. pressure.html).

\section{b. Methods}

To extract interannual variability signals, the linear trend and the annual cycle are first removed, and then a 13-yr running mean is also removed from the historical and the RCP8.5 runs. We denote the prior-ENSO year as year (0) and its decay year as year (1). The standardized Niño-3.4 index [defined as $\mathrm{D}(0) \mathrm{JF}(1)$ SST anomalies averaged over the region $5^{\circ} \mathrm{S}-5^{\circ} \mathrm{N}, 120^{\circ}-$ $\left.170^{\circ} \mathrm{W}\right]$ is regressed onto the interannual anomalies of SST, circulation, and other variables. These regression patterns display the structural changes in the ENSOinduced variability in these variables and also contain amplitude changes of ENSO variability. The unstandardized Niño-3.4 index is also regressed onto the interannual anomalies of SST to display the changes in ENSO-related SST without considering ENSO amplitude change. The changes in the ENSO-induced variability in the future are defined as the differences between the variability in the RCP 8.5 and the historical (1971-2000) runs.

The regression is performed for the anomalies in the individual models separately, and then the regressed patterns in all models are averaged to define the multimodel ensemble mean (MME). The MME is used to reduce the influence of model bias. The intermodel consensus is defined as the percentage of models that agree on the sign of change with the MME. For the vector field, the intermodel consensus of the zonal and the meridional components are calculated separately, and the maximum of the two components is referred to as the intermodel consensus of the vector field. A threshold of $68 \%$ intermodel consensus is equal to $95 \%$ statistical significance calculated by the Student's $t$ test, assuming that the models are independent of each other (Power et al. 2012). The change is considered significant if at least 13 of the 18 models agree on the sign of change.

\section{c. Model selection}

The simulation skill of El Niño-induced JJA(1) NWPAC anomalies is applied to select reliable models by comparing the anomalous NWPAC in the observations and the historical run. We define an NWPAC anomaly index as the difference of 850-hPa El Niñorelated zonal wind anomalies between a northern region $20^{\circ}-30^{\circ} \mathrm{N}, 110^{\circ}-140^{\circ} \mathrm{E}$ and a southern region $5^{\circ}-15^{\circ} \mathrm{N}$, $100^{\circ}-130^{\circ} \mathrm{E}$, following Wang et al. (2001) with a reversed sign. The NWPAC anomaly indices in the 30 CGCMs are shown in Fig. 1a. The 18 models in which simulated NWPAC anomaly indices are greater than 0.4 are selected as high-skill models. The NWPAC anomaly index in the MME of 18 models is similar to that in observations, and the intermodel spread is small. [The evolutions of NWPAC anomalies from $\mathrm{D}(0) \mathrm{JF}(1)$ to JJA(1) of the 18 models are shown in Fig. S1 of the supplemental material.] And we also tried to select models with different criteria, 22 models with NWPAC anomaly indices $>0.3$, and 15 models with NWPAC anomaly indices $>0.5$. The results (not shown) are not sensitive to the selections. Compared with the observed NWPAC anomaly index, the simulated indices in the remaining 12 models (denoted by an asterisk in Table 1) show an apparent bias. In CanESM2, CMCC-CM, CSIRO Mk3.6.0, INM-CM4.0, IPSL-CM5A-MR, MPI-ESM-LR, and MPI-ESM-MR, the NWPAC anomaly indices are negative, and the NWPAC anomaly indices in the other five models are slightly greater than zero. Compared with the NWPAC anomaly pattern in the observations (Fig. 1b), the anomalous NWPAC in the MME of the 12 low-skill models shifts eastward and an anomalous cyclone appears over the South China Sea, and significant westerly wind anomalies dominate over the tropical Indo-western Pacific, exceeding 68\% intermodel consensus (Fig. 1d). There are significant biases in the simulated JJA(1) El Niño-related NWPAC anomalies in the MME of the 12 low-skill models (Fig. 1d), whereas the El Niño-induced NWPAC pattern and amplitude are reproduced well in the MME of the other 18 high-skill models (Fig. 1c).

Jiang et al. (2017) suggested that some of the CGCMs in CMIP5 are not able to reproduce the NWPSMENSO teleconnection well because of the poor skill in simulating the evolution of ENSO. Furthermore, the unabated warm SST anomalies in JJA(1) in the equatorial western Pacific can interfere with the NWPSM in 
(a) NWPAC anomaly index

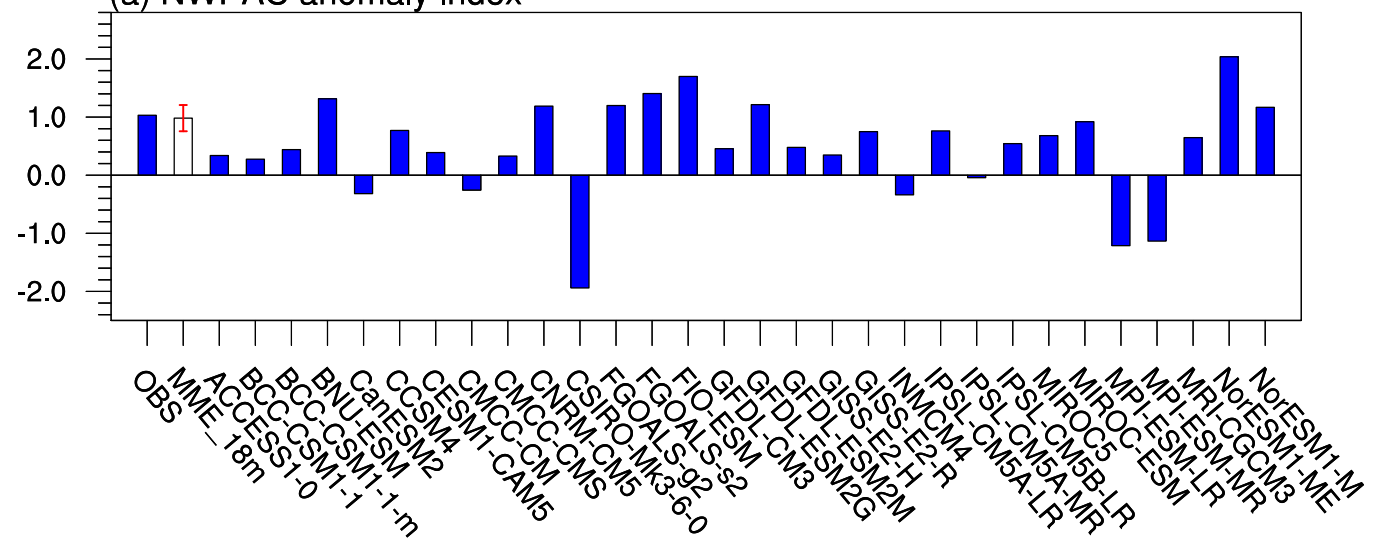

(b) OBS

ENSO wind

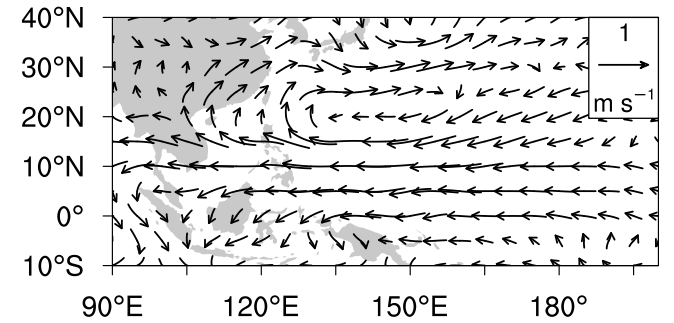

(c) MME_18m

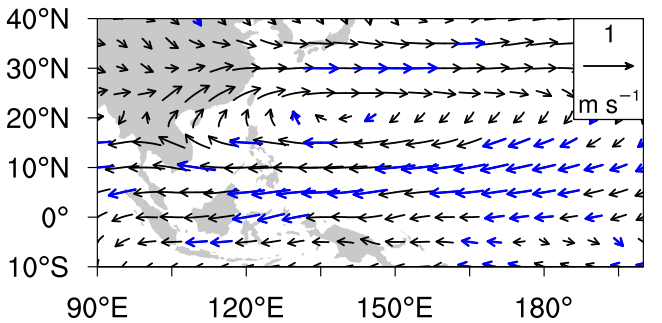

(d) MME_12m

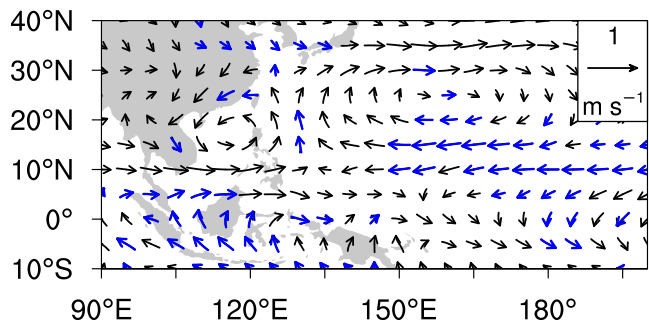

FIG. 1. (a) ENSO-regressed NWPAC anomaly indices from the observations, and the MME of the 18 selected models and 30 CGCMs. Regressed anomalies of JJA(1) 850-hPa wind anomalies on the D(0)JF(1) standardized Niño-3.4 index in (b) observations, (c) the MME of the 18 selected models, and (d) the MME of the 12 unselected models in the historical run for the period 1971-2000. The region with blue arrows in (c),(d) indicates that the sign of the MME projected change agrees in more than $68 \%$ of models.

response to El Niño. Figure 2 shows the temporal evolution of the ENSO-related SST anomalies from the mature winter to the decaying summer in 1971-2000 in observations, the MME of the 18 high-skill models, and the MME of the 12 low-skill models. In the MME of the high-skill models, the ENSO-related SST anomalies in the tropical Pacific gradually decay in the following spring and summer, and more than 13 models agree the signs of the MME change (Figs. 2d-f), realistically reproducing the observed evolution of ENSO (Figs. 2a-c). (The evolutions of SST anomalies of the 18 models are individually shown in Fig. S2 of the supplemental material.) In the MME of the low-skill models, however, the warm SST anomalies in the equatorial western $\mathrm{Pa}$ cific persist in the El Niño decaying summer, exceeding
$68 \%$ intermodel consensus (Figs. $2 \mathrm{~g}-\mathrm{i}$ ). Therefore, we select the 18 high-skill models and exclude the 12 lowskill models in the following analysis to reduce the influence of the model biases. All results are based on the MME of the selected 18 high-skill models.

\section{Results}

\section{a. Future changes of the NWPAC in response to El Niño}

Figure 3a shows the MME changes in the El Niñoinduced JJA(1) 850-hPa wind and SLP anomalies during 2071-2100 considering ENSO amplitude change. A significant cyclone dominates over the NWP where there is 
(a) ENSO SST_OBS D(0)JF(1)

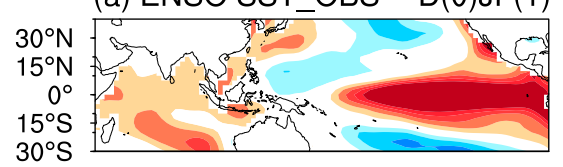

(b) ENSO SST_OBS MAM(1)

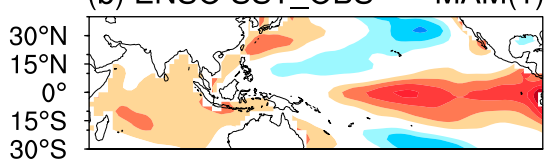

(c) ENSO SST_OBS JJA(1)

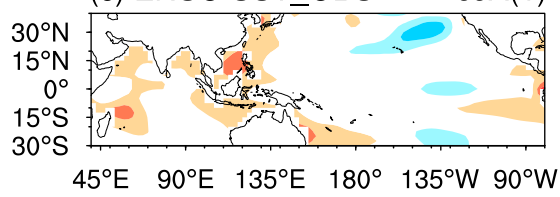

(d) ENSO SST $18 \mathrm{~m} \quad \mathrm{D}$ (0)JF(1)

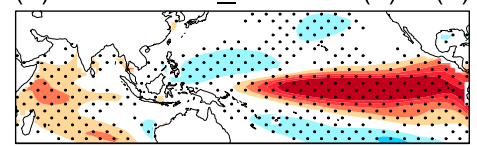

(e) ENSO SST_18m MAM(1)
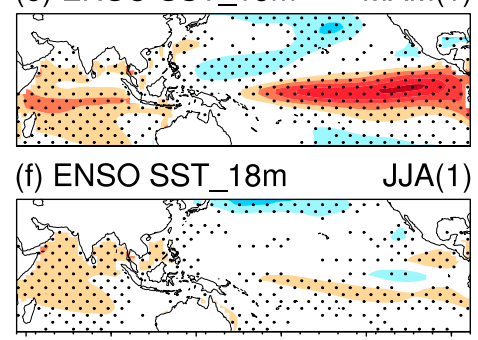

$45^{\circ} \mathrm{E} \quad 90^{\circ} \mathrm{E} \quad 135^{\circ} \mathrm{E} \quad 180^{\circ} 135^{\circ} \mathrm{W} 90^{\circ} \mathrm{W}$ (g) ENSO SST_12m D(0)JF(1)

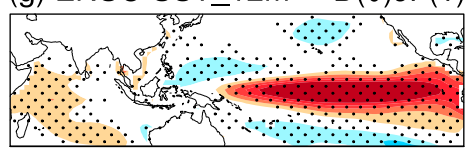

(h) ENSO SST_12m MAM(1)

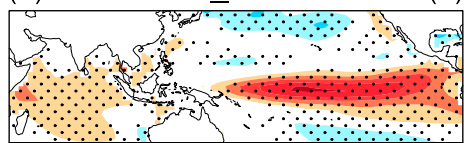

(i) ENSO SST_12m JJA(1)

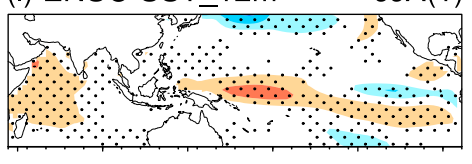

$45^{\circ} \mathrm{E} \quad 90^{\circ} \mathrm{E} \quad 135^{\circ} \mathrm{E} \quad 180^{\circ} 135^{\circ} \mathrm{W} 90^{\circ} \mathrm{W}$

\section{$\begin{array}{llllllllllll}-0.5 & -0.4 & -0.3 & -0.2 & -0.1 & 0 & 0.1 & 0.2 & 0.3 & 0.4 & 0.5 & { }^{\circ} \mathrm{C}\end{array}$}

FIG. 2. Regressed anomalies of SST from $\mathrm{D}(0) \mathrm{JF}(1)$ to JJA(1) on the $\mathrm{D}(0) \mathrm{JF}(1)$ standardized Niño-3.4 index in (a)-(c) observations, (d)-(f) the MME of the 18 selected models, and (g)-(i) the MME of the 12 unselected models for the period 1971-2000. The stippled area in (d)-(i) indicates the region where the sign of the MME projected change agrees in more than $68 \%$ of models.

an anomalous NWPAC originally, and an anticyclonic shear appears to the north of the cyclone. The projected ENSO-induced JJA(1) circulation change pattern is almost opposite in phase compared with that in Figs. 1b,c, which suggests that the response of the NWPAC to El Niño during post-El Niño summers will be weakened in the future. Moreover, the diminished response is not only embodied in the $850-\mathrm{hPa}$ circulation anomalies but also appears in the SLP anomaly pattern.

To show that this weakening is forced by global warming, but is not dependent on the selected time period, the period of 2011-2100 in the RCP8.5 run is divided into seven segments of 30 years in length with a 10-yr gap (i.e., 2011-40, 2021-50, 2031-60, ... , 20712100), representing the future climate during different periods under global warming. In each segment, the methods described in section $2 \mathrm{~b}$ are repeated, and then we calculate the linear regression of the seven segments. Figure $3 b$ displays the linear trend of changes in the ENSO-driven 850-hPa circulation and the SLP anomalies from 2011-40 to 2071-2100. The diminished patterns of the NWPAC and SLP anomalies are significant and most regions exceed the $95 \%$ confidence level. The results indicate that the diminished pattern of the NWPAC in response to El Niño becomes more significant as the global warming intensifies. Hereinafter, we will only compare the differences between the variability in 2071-2100 and in 1971-2000 unless otherwise noted.

We also analyze the JJA(1) 850-hPa wind and SLP anomalies regressed onto the unstandardized Niño-3.4 index during 1971-2000 and 2071-2100, which does not take the ENSO amplitude change into account. There is still a pronounced weakening of the NWPAC and SLP anomalies in the projected MME change pattern (Fig. 3c), which is similar to that in Fig. 3a. This suggests that the weakening of the JJA(1) NWPAC is robust under global warming regardless of whether ENSO amplitude change is included.

\section{b. Mechanism for the weakening of the NWPAC in response to El Niño}

Previous studies have found that the zonal contrast between the anomalous TIO warming and the anomalous NWP cooling plays a crucial role in maintaining the anomalous NWPAC during post-El Niño summers (Terao and Kubota 2005; Ohba and Ueda 2006; Kosaka et al. 2013; Xie et al. 2016). The cold NWP SST anomalies force the NWPAC as a cold atmospheric Rossby wave (Wang et al. 2000). The TIO warming triggers a warm atmospheric Kelvin wave, suppressing convection over the NWP and maintaining the NWPAC (Xie et al. 2009). Figure 4 shows the relationship between the JJA(1) anomalous NWPAC and the JJA(1) SST anomalies in the TIO-NWP, defined as the SST differences between the TIO $\left(10^{\circ} \mathrm{S}-20^{\circ} \mathrm{N}, 50^{\circ}-120^{\circ} \mathrm{E}\right)$ and NWP $\left(5^{\circ}-20^{\circ} \mathrm{N}\right.$, $130^{\circ} \mathrm{E}-180^{\circ}$ ), and the TIO and the NWP in the historical runs of the 18 models, respectively. The correlation coefficients of anomalous NWPAC with the SST anomalies in the TIO-NWP and the TIO are 0.56 and 0.60 , respectively, exceeding the $95 \%$ confidence level. This suggests that the close relationships between the zonal contrast of interbasin SST anomalies, TIO SST anomalies, and the NWPAC are captured well in the 18 selected models. The correlation coefficient of anomalous NWPAC 
(a) ENSO SLP\&wind change

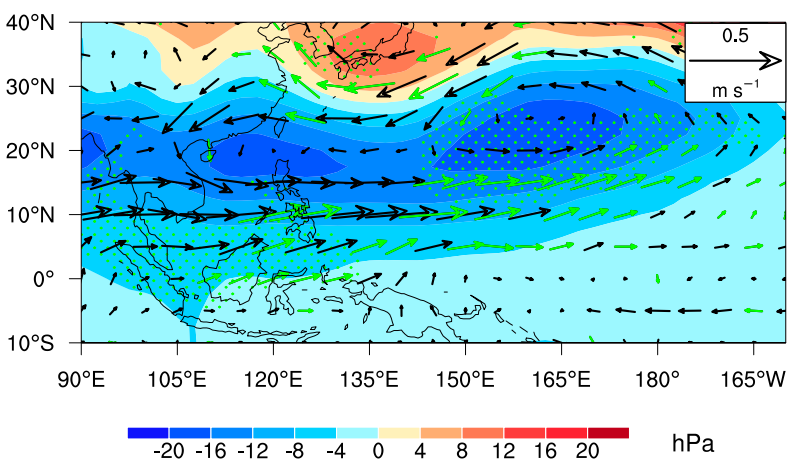

(b) Trend

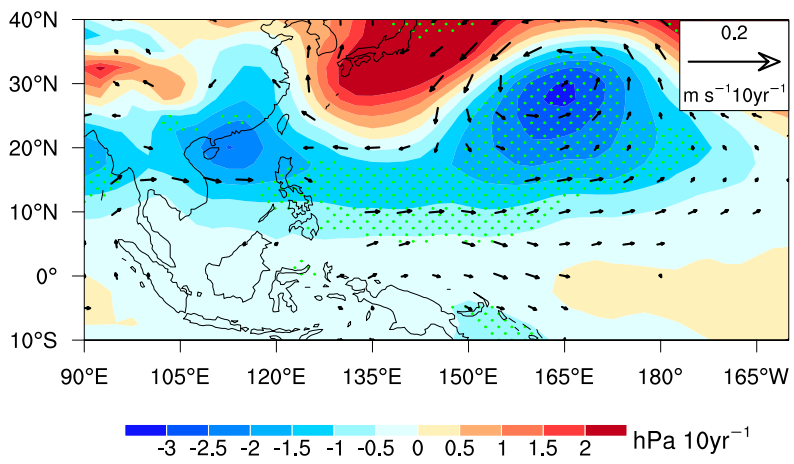

(c) Unstd ENSO SLP\&wind change

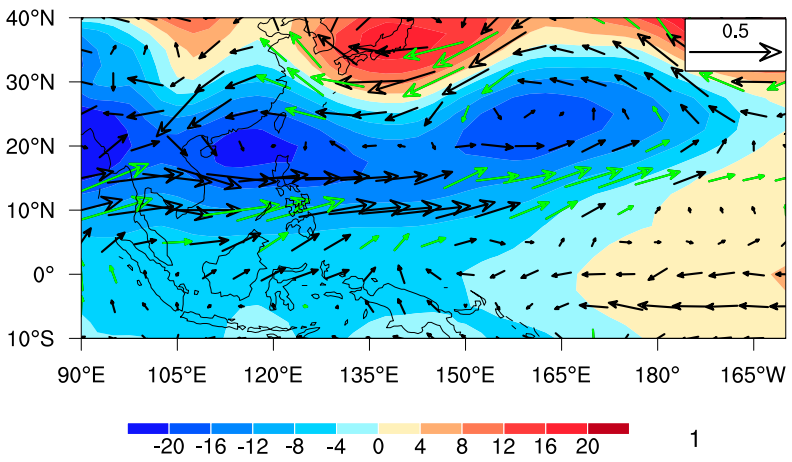

FIG. 3. (a) Changes in ENSO-induced JJA(1) SLP anomalies and 850-hPa wind anomalies in the RCP8.5 run for the period 2071-2100 relative to those in 1971-2000. The stippled green area indicates the region where the sign of the MME projected change agrees in more than 13 models. (b) Trend of the changes in the ENSO-induced SLP and wind anomalies from 2011-40 to 2071-2100 relative to those in 1971-2000. Green dots and black arrows indicate where the significance exceeds the $95 \%$ confidence level. (c) As in (a), but regressed on the $\mathrm{D}(0) \mathrm{JF}(1)$ unstandardized Niño-3.4 index.

with the NWP SST anomalies is -0.36 , which does not exceed 95\% confidence level. Wu et al. (2010) suggested that the cold NWP SST anomalies play a crucial role in maintaining the NWPAC in early summer, and then the local forcing effect gradually declines in middle and later summer because of the decay of local cold SST anomalies in observations. However, it does not mean the NWP SST anomalies will not play a more important role in influencing the NWPAC anomalies when NWP SST anomalies show remarkable changes under global warming. These mechanisms imply that the diminished NWPAC in response to El Niño may be related to the changes in the El Niño-related SST gradient between the TIO and the NWP under global warming.

Figures 5a-c show the projected MME changes of the ENSO-related SST anomalies from D(0)JF(1) to JJA(1) when considering the ENSO amplitude change. The change pattern of tropical SST anomalies is approximately opposite in phase from $\mathrm{D}(0) \mathrm{JF}(1)$ to $\mathrm{JJA}(1)$ relative to the historical ENSO-related SST pattern in Figs. 2d-f, which indicates that the tropical ENSO-related SST anomalies are, in general, weakened under global warming. The weakening of the SST anomalies in the tropical western Pacific extends from the equatorial western Pacific during the El Niño mature winter to the NWP (the black box in Fig. 5c) during the El Niño decaying summer. The changes in SST anomalies in the equatorial Indian Ocean are weakened during the El Niño mature winter and the following spring, and are negligible during the post-El Niño summers. Although the changes in SST anomalies in the $\mathrm{TIO}$ are not uniform and negligible, there is still significant weakening of the zonal contrast between the TIO SST anomalies and the NWP SST anomalies.

There is significant weakening of the SST anomalies in the tropical eastern Pacific during the El Niño mature phase, which implies a weakened ENSO amplitude under global warming (Fig. 5a). This result is consistent with the MME conclusion in recent studies using a similar CMIP5 simulation (Kim et al. 2014). Although Kim et al. (2014) suggested that the trend in ENSO amplitude over the entire twenty-first century is not unidirectional, we can find a decrease of ENSO amplitude in the period 20712100 relative to those in 1971-2000. The decreased ENSOrelated SST amplitude in the multimodel ensemble of CMIP5 is a common result in recent studies (Power et al. 2013; Cai et al. 2014; Kim et al. 2014; Huang and Xie 2015; Huang 2016), although the ENSO-related SST amplitude changes are still controversial among the models and scenarios (Collins et al. 2010; Power et al. 2013). The common decreased ENSO-related SST amplitude does not contradict the significant enhancement of extreme ENSO, when the extreme ENSO is defined based on the ENSOrelated rainfall in the tropical eastern Pacific (Power et al. 2013; Cai et al. 2014; Huang and Xie 2015; Huang 2016).

To distinguish the weakening of the NWP and TIO SST anomalies during post-El Niño summers that is induced by the weakening of the ENSO SST, or by the changed ENSO processes that influence the SST anomalies in the NWP and the TIO, we analyze the change in the SST anomalies regressed onto the unstandardized 
(a)

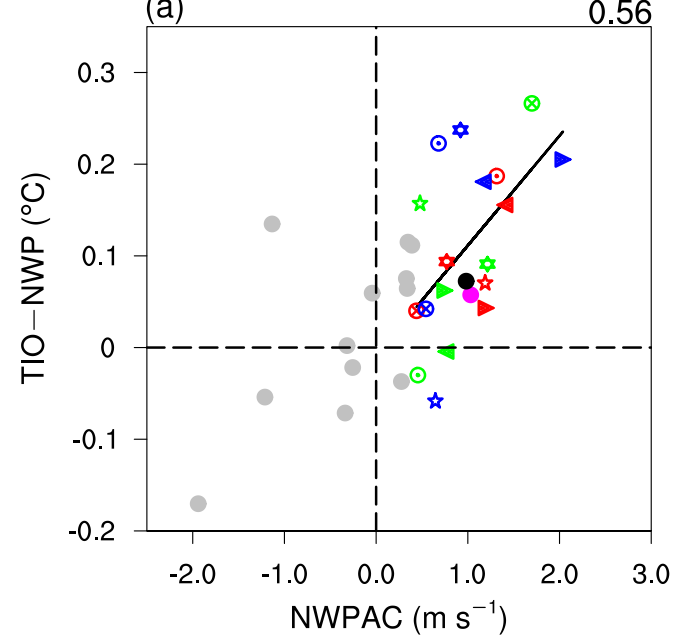

(c)

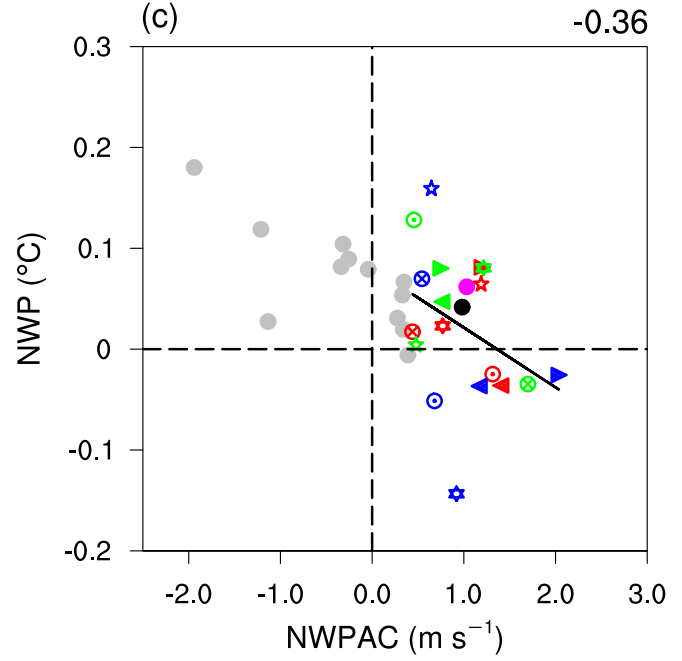

(b)

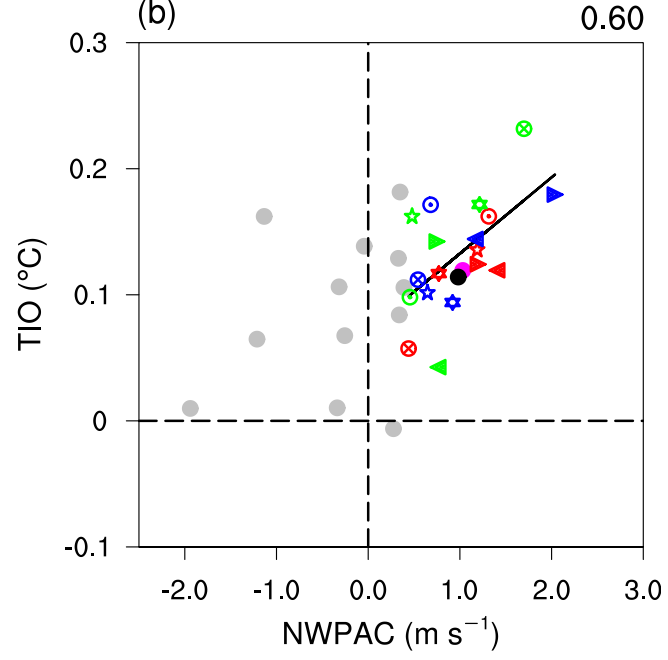

NorESM1-M

- NorESM1-ME

* MRI-CGCM3

- MIROC-ESM

- MIROC5

(2) IPSL-CM5B-LR

IPSL-CM5A-LR

- GISS-E2-R

* GFDL-ESM2M

* GFDL-ESM2G

FIG. 4. Scatterplots of JJA(1) NWPAC indices vs synchronous (a) TIO - NWP SST anomalies, (b) TIO SST anomalies, and (c) NWP SST anomalies in 30 CMIP5 models in the historical run. Black lines denote the linear fitting between the horizontal and vertical coordinates of the 18 selected models. Their MME is displayed by black dots and their correlation coefficient is shown in the top-right corner. Pink dots represent the observations. Gray dots represent the 12 unselected models.

Niño-3.4 index (Figs. 5d-f). There are no apparent changes in the SST anomalies in the tropical eastern Pacific during the El Niño mature phase (Fig. 5d). The changes in the ENSO-related SST anomalies during the El Niño decaying spring and summer (Figs. 5e,f) are generally consistent with the changes shown in Figs. 5b,c: not uniform and significant changes in the TIO, and significant warming in the NWP. This indicates that the weakening of the NWP and TIO SST anomalies in response to the ENSO SST anomalies may be associated with the potentially weakened ENSO SST anomalies, but are primarily modulated by the changed ENSO processes that influence the SST anomalies in the NWP and the TIO.
The changes in the TIO and NWP SST anomalies and their difference (TIO - NWP) in the MME and the 18 individual models are shown in Fig. 6. The warming changes in the NWP SST anomalies are robust among the models: 14 models simulate changes in the NWP SST anomalies consistent with the MME result (exceeding $78 \%$ intermodel consensus), regardless of whether the ENSO amplitude change is considered. The warm TIO SST anomalies display a slight decrease in the MME and a remarkable spread among the 18 models. However, despite the large uncertainty in the TIO SST anomaly changes, the changes in the SST anomaly gradient between the TIO and the NWP exhibit a robust decrease under global warming, and there are 13 (12) 
(a) ENSO SST change

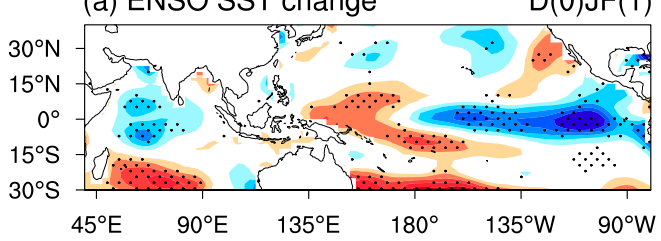

(b) ENSO SST change

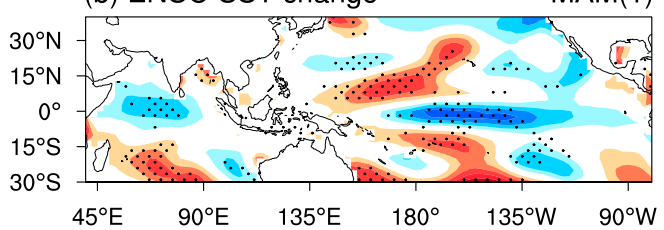

(c) ENSO SST change

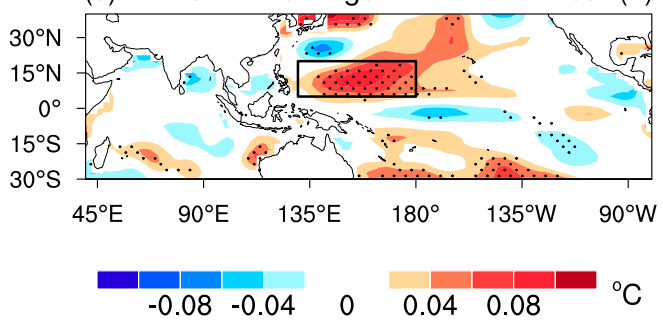

(d) Unstd ENSO SST change

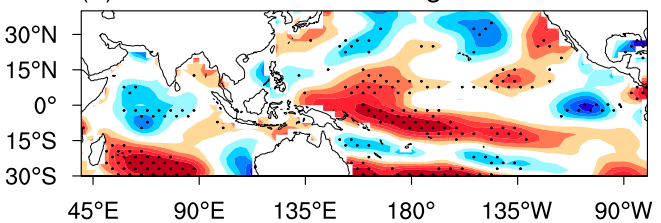

(e) Unstd ENSO SST change

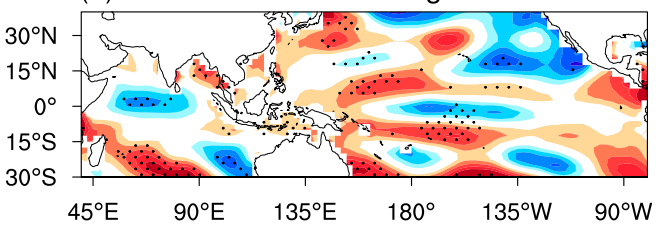

(f) Unstd ENSO SST change

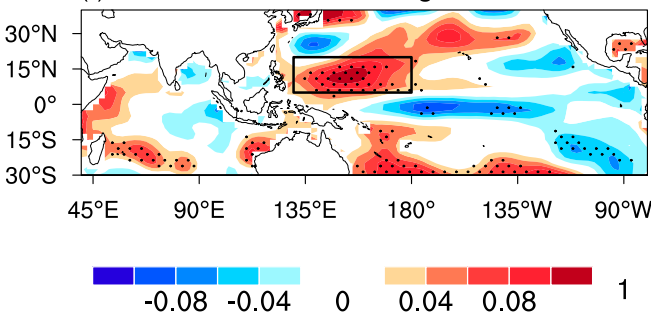

FIG. 5. Changes in the ENSO-related SST anomalies in the RCP8.5 run for 2071-2100 relative to those in 19712000. The SST is regressed (a)-(c) on the standardized Niño-3.4 index and (d)-(f) on the unstandardized Niño-3.4 index. The stippled region indicates where the sign of the MME projected change agrees in more than 13 models. The black boxes in (c),(f) highlight the NWP region.

models among the 18 models projecting a clear decrease with (without) the ENSO amplitude change. The zonal contrast between the anomalous TIO warming and the anomalous NWP cooling decreases significantly, which is expected by the weakening of the NWPAC. Figure S3 in the supplemental material shows the relationships between the JJA(1) NWPAC changes and the SST anomalies changes in the TIO - NWP, the TIO, and the NWP. Their correlation coefficients are 0.76 , 0.55 and -0.50 , respectively. Meanwhile, the correlations are $0.78,0.55$ and -0.44 when the effect of ENSO amplitude changes is removed (Fig. S4 in the supplemental material). All of them exceed $90 \%$ confidence level. It suggests that the weakening of NWPAC is closely related to the robust decrease of the El Niñorelated SST gradient between the TIO and the NWP under global warming.

In the next two subsections, we explore the possible mechanisms involved in the response of the NWP and TIO SST anomalies to ENSO SST anomalies under global warming. To eliminate the possible effects of the ENSO amplitude change, the unstandardized Niño-3.4 index is regressed onto the anomalies of the corresponding variables to display the changes in the ENSOrelated variability of these variables without the effect of possible changes in the ENSO amplitude.

\section{c. Possible mechanisms of the weakened response of the NWP SST anomalies to ENSO SST anomalies}

Wang et al. (2000) suggested that the local windevaporation-SST (WES) (Xie and Philander 1994) feedback in the NWP is the critical process for the NWP cooling in response to the ENSO SST anomalies. We evaluate the effect of the WES feedback with an LHF decomposition, where LHF is given by

$$
Q_{E}=\rho_{a} L C_{E} W\left[q_{s}(T)-\mathrm{RH} q_{s}(T-\Delta T)\right] .
$$

Here, $\rho_{a}$ is surface air density, $L$ represents the latent heat of evaporation, $C_{E}$ is the transfer coefficient, $W$ is surface wind speed, $q_{s}(T)$ is the saturated specific humidity, $\mathrm{RH}$ represents surface relative humidity, $T$ is $\mathrm{SST}$, and $\Delta T$ is the sea-air temperature difference. LHF can be divided into two parts: atmospheric forcing $Q_{\text {atm }}$ and the oceanic response $Q_{\text {oce }}$, wherein the latter is defined as a Newtonian cooling term by linearizing Eq. (1):

$$
Q_{\mathrm{oce}}^{\prime}=\bar{Q}_{E}\left(\frac{1}{\bar{q}_{s}} \frac{d \bar{q}_{s}}{d T}\right) T^{\prime}
$$

where the overbar and prime represent the mean and perturbation, respectively. The atmospheric forcing term $Q_{\mathrm{atm}}^{\prime}=Q_{E}^{\prime}-Q_{\mathrm{oce}}^{\prime}$ is due to changes in wind speed, 

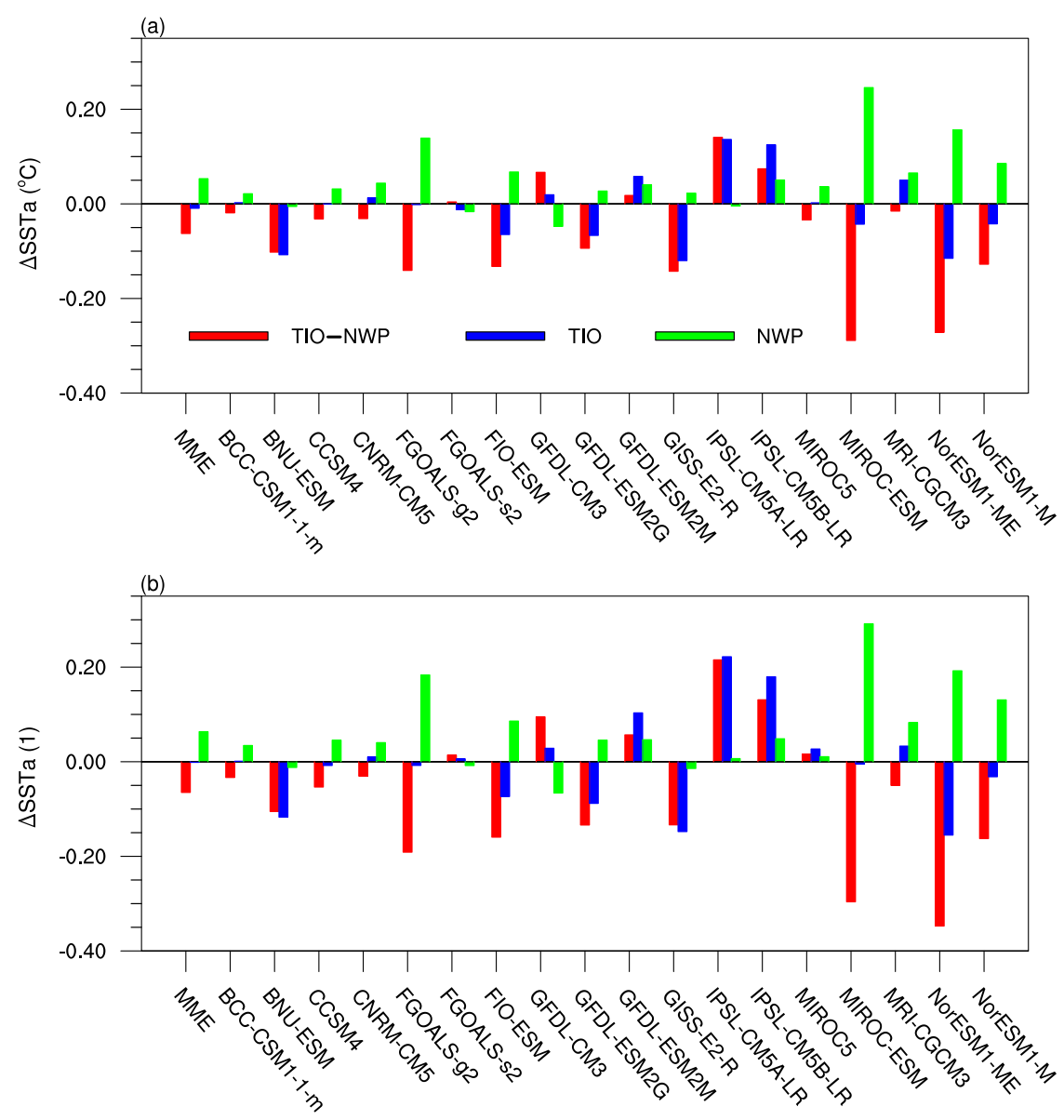

FIG. 6. Changes in the JJA(1) SST anomalies of the TIO, NWP, and their difference (TIO NWP) response to ENSO in the 18 selected models and their MME. (a) The effect of ENSO amplitude changes is included, and (b) the effect of ENSO amplitude changes is removed.

relative humidity, and the air-sea temperature difference, commonly regarded as a measure of WES feedback [see Du and Xie (2008) for details].

Figure 7 shows the ENSO-driven $850-\mathrm{hPa}$ wind anomalies from $\mathrm{D}(0) \mathrm{JF}(1)$ to $\mathrm{JJA}(1)$ in the historical run and the resultant changes in the future. The corresponding atmospheric forcing of the LHF anomalies is shown in Fig. 8. The northeasterly (southwesterly) anomalies on the southeastern (northwestern) flank of the NWPAC anomalies can accelerate (decelerate) the mean northeast trades (Figs. 7a,b), and a corresponding dipole pattern of atmospheric forcing of the LHF anomaly appears over the NWP (Figs. 8a,b). The local WES feedback contributes to the formation of cold NWP SST anomalies. Comparing Figs. 7a and 7d, we can see that the 850-hPa wind anomalies over the NWP will be weakened during the El Niño mature phase under global warming. A recent study by Huang et al. (2017) proposed that the atmospheric circulation in response to ENSO will likely decrease under global warming, which may be responsible for the $\mathrm{D}(0) \mathrm{JF}(1)$ weakened NWPAC. In addition, $\mathrm{Wu}$ et al. (2017) suggested that remote forcing from the equatorial central-eastern Pacific plays an important role in maintaining the NWPAC during the El Niño mature winter and the following spring. The MAM(1) weakened SST anomalies in the equatorial central-eastern Pacific may also favor the MAM(1) weakened NWPAC (Figs. 5e and 7e). Correspondingly, the release of LHF anomalies over the tropical NWP region is decreased because of the weakening of NWPAC (Figs. 8d,e), heating the SST in the tropical NWP region (Figs. 5d,e). In turn, the resulting warming change in the tropical NWP could further weaken the NWPAC. The decreased local air-sea interaction will contribute to the weakening of the cold NWP SST anomalies during post-El Niño summers in the future.

The changes in NWP SST anomalies could be influenced by multiple factors. We can find that the changes in wind anomalies and atmospheric forcing of LHF anomalies shown in Figs. 7 and 8 are not completely in 
(a) Unstd ENSO wind

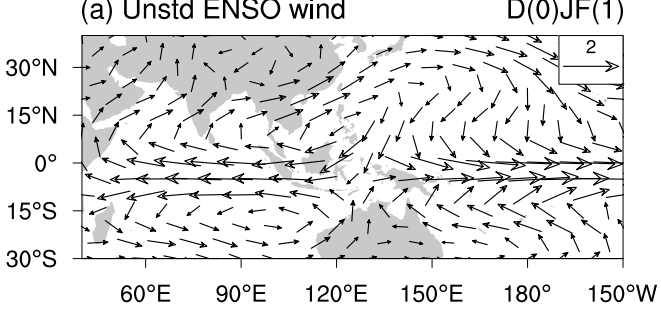

(b) Unstd ENSO wind

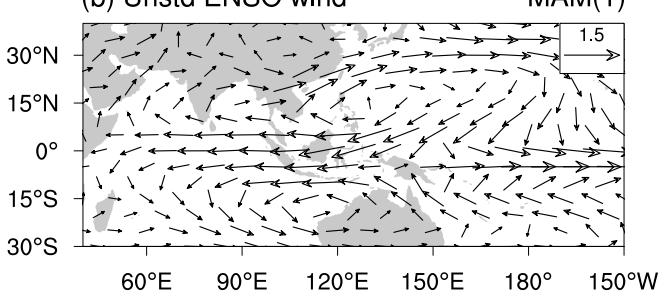

(c) Unstd ENSO wind

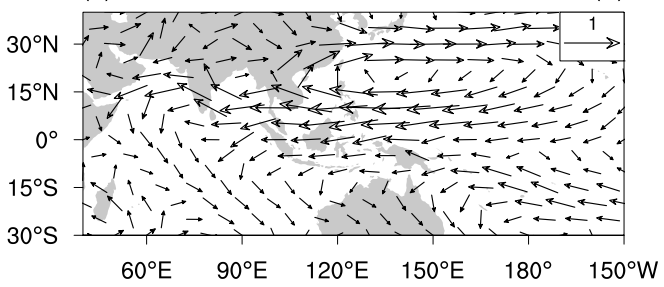

(d) Unstd ENSO wind change

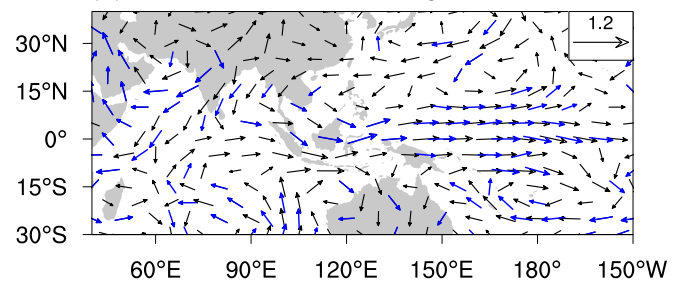

(e) Unstd ENSO wind change

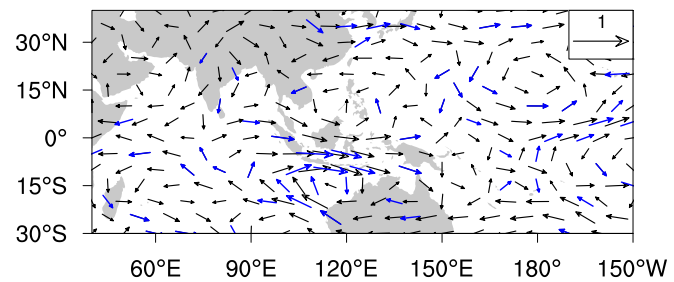

(f) Unstd ENSO wind change

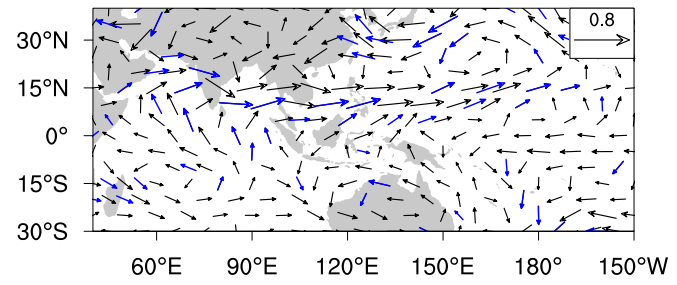

FIG. 7. (a)-(c) Regressed anomalies of 850-hPa wind from D(0)JF(1) to JJA(1) on the D(0)JF(1) unstandardized Niño-3.4 index in the historical run (1971-2000). (d)-(f) The corresponding changes in the ENSO-driven 850-hPa wind anomalies from $\mathrm{D}(0) \mathrm{JF}(1)$ to JJA(1) in the RCP8.5 run (2071-2100) relative to 1971-2000. The region with blue arrows in (d)-(f) indicates where the sign of the MME projected change agrees in more than 13 models.

phase with the changes in SST anomalies shown in Fig. 5. Thus, we also perform a surface heat flux analysis to understand the possible causes of the weakened NWP SST anomalies. The net surface heat flux is $Q_{\text {net }}=$ $Q_{\mathrm{SW}}+Q_{\mathrm{LW}}-Q_{\mathrm{LHF}}-Q_{\mathrm{SHF}}$, where $Q_{\mathrm{sw}}, Q_{\mathrm{LW}}, Q_{\mathrm{LHF}}$, and $Q_{\mathrm{SHF}}$ denote net $\mathrm{SW}$ radiation, net $\mathrm{LW}$ radiation (positive downward), LHF, and SHF at the surface (positive upward), respectively. Figure 9 shows the ENSO-related net surface heat flux anomalies from $\mathrm{D}(0) \mathrm{JF}(1)$ to JJA(1) in observations, the historical run, and the corresponding changes in the future. The negative surface heat flux anomalies appear over the NWP from the El Niño mature winter to the following summer, which could contribute to the formation of the cold NWP SST anomalies (Figs. 9a-f). Compared with the historical net surface heat flux anomalies shown in Figs. $9 \mathrm{~d}-\mathrm{f}$, there is a clear positive change in the net surface heat flux anomalies over the NWP in $\mathrm{D}(0) \mathrm{JF}(1)$ and MAM(1) under global warming (Figs. 9g,h). The positive changes in the net surface heat flux anomalies over the NWP also persist into the following summer (as shown in the black boxes of Figs. 9f,i), which contributes to the weakening of the cold NWP SST anomalies during post-El Niño summers.
In conclusion, the weakening of the atmospheric circulation in response to ENSO under global warming leads to diminished NWPAC anomalies in the El Niño mature phase, and the weakened SST anomalies in the equatorial central-eastern Pacific may give rise to the weakened NWPAC anomalies in the following spring. The resulting weakened local WES feedback favors the weakening of the cold NWP SST anomalies in the following spring and summer. Moreover, the positive changes of the net surface heat flux anomalies also make a negative contribution to the formation of the cold NWP SST anomalies during post-El Niño summers.

\section{d. Possible mechanisms of the indistinctive response of TIO SST anomalies to ENSO SST anomalies}

The projected MME change in JJA(1) TIO SST anomalies shows a nonuniform and indistinctive change in most regions of the TIO (Fig. 5f). Previous studies have indicated that the TIO basinwide warming is not uniform and is the result of the combined effects of ENSO-induced surface heat flux anomalies (Klein et al. 1999; Lau and Nath 2003), the TT mechanism (Chiang and Sobel 2002; Chiang and Lintner 2005), ocean dynamical processes (Huang and Kinter 2002; Xie et al. 
(a) Unstd ENSO $Q_{\text {atm }}$

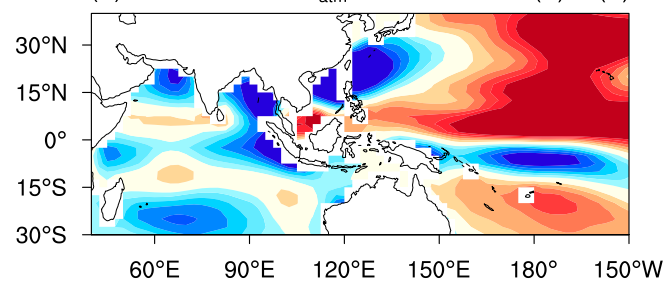

(b) Unstd ENSO $Q_{\text {atm }}$

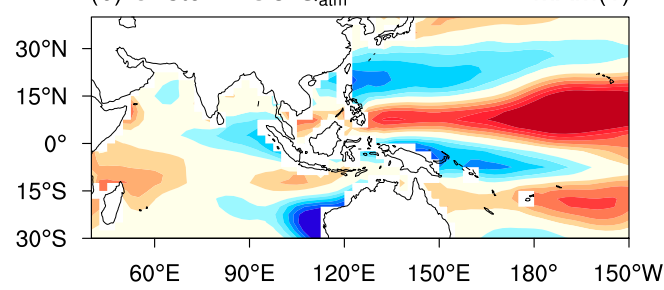

(c) Unstd ENSO Q

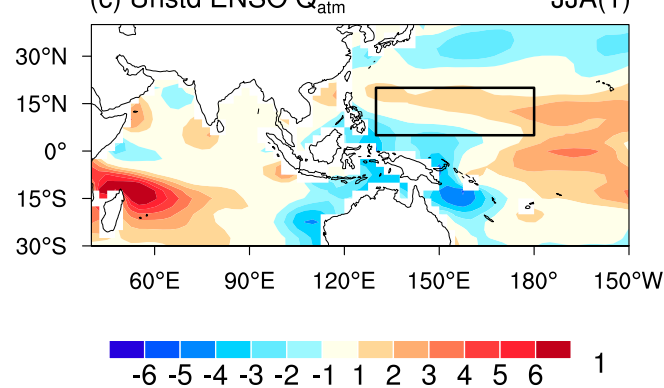

(d) Unstd ENSO $Q_{\text {atm }}$ change

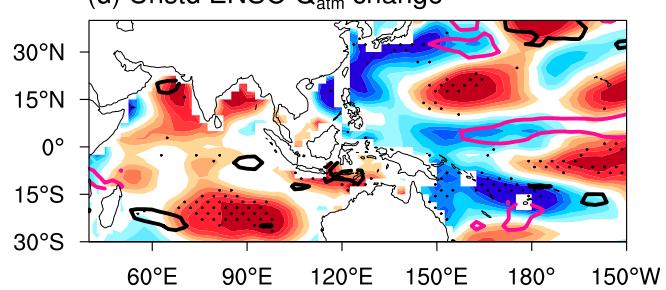

(e) Unstd ENSO $Q_{\text {atm }}$ change

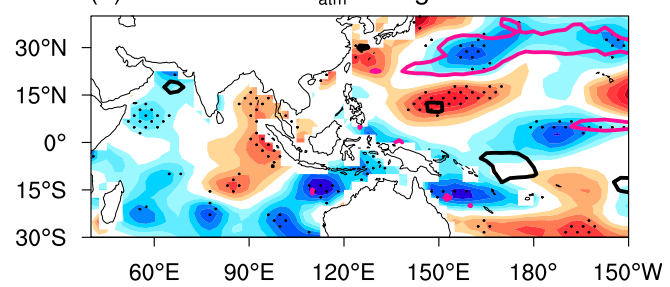

(f) Unstd ENSO $Q_{\text {atm }}$ change

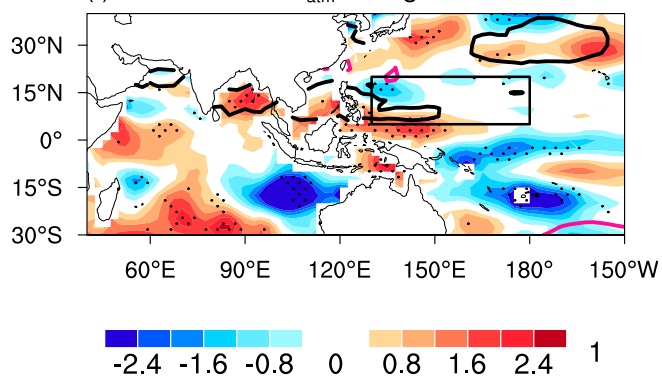

FIG. 8. (a)-(c) Regressed anomalies of the atmospheric forcing part of the LHF (positive upward) from D(0)JF(1) to JJA(1) on the D(0)JF(1) unstandardized Niño-3.4 index in the historical run for 1971-2000. (d)-(f) The corresponding ENSO-induced LHF changes (shading) and the surface wind speed changes [contours; black (pink) lines denote $+0.15(-0.15) \mathrm{m} \mathrm{s}^{-1}$ contours of surface wind speed change] in 2071-2100 relative to those in 1971-2000. The stippled region in (d)-(f) indicates where the sign of the MME projected change agrees in more than 13 models. The black boxes in (c),(f) highlight the NWP region.

2002), and an antisymmetric pattern of atmospheric circulation (Du et al. 2009).

Klein et al. (1999) found that the ENSO-related JJA (1)-increased net surface heat flux anomalies over the eastern Indian Ocean and the western Pacific could enhance SST anomalies there, which is captured in the historical run of the MME of the 18 models (Figs. 9c,f). In Fig. 9i, there is a pronounced decrease in the net surface heat flux anomalies over most regions of the TIO during post-El Niño summers under global warming, which is conducive to the weakening of the warm TIO SST anomalies in the future. In the NIO and the eastern Indian Ocean, particularly, the pattern of change of the net surface heat flux anomalies is consistent with the pattern of change of SST anomalies in Fig. 5f. This suggests that the surface heat flux anomalies may play a crucial role in changing the SST anomalies in these regions in the future. In some regions, the changes in net surface heat flux anomalies are not perfectly in phase with the changes in SST anomalies, possibly induced by other factors.
In terms of the TT mechanism, during the peak of El Niño, the tropospheric temperature over the tropical eastern Pacific can be increased because of the air-sea temperature and humidity differences, and then equatorial planetary waves propagate the El Niño-induced warm tropospheric temperature anomalies from the tropical eastern Pacific to the TIO (Figs. 10a-c). Moist convective processes, which can drive the boundary layer moist static energy to vary with the free tropospheric moist static energy, can increase the TIO SST anomalies in post-El Niño summers (Chiang and Sobel 2002; Chiang and Lintner 2005). Hu et al. (2014) found that the tropospheric temperature in response to the SST anomalies is strengthened regardless of the ENSO amplitude change under global warming. Figures $10 \mathrm{~d}-\mathrm{f}$ show the projected MME changes in the ENSO-related tropospheric temperature anomalies from $\mathrm{D}(0) \mathrm{JF}(1)$ to JJA(1) without taking the ENSO amplitude change into account. The tropospheric temperature anomalies are clearly strengthened over the whole tropics from 
(a) Unstd ENSO $Q_{\text {net }} \quad \mathrm{D}(0) \mathrm{JF}(1)$

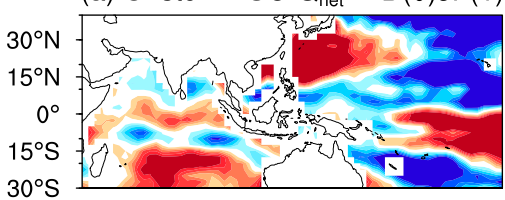

(d) Unstd ENSO Q

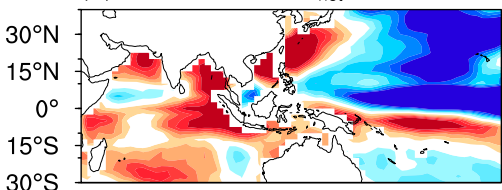

(g) Unstd ENSO $Q_{\text {net }}$ change

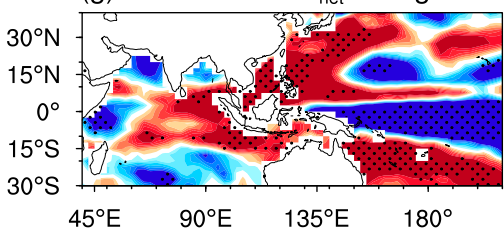

(b) Unstd ENSO $Q_{\text {net }} \quad \operatorname{MAM}(1)$

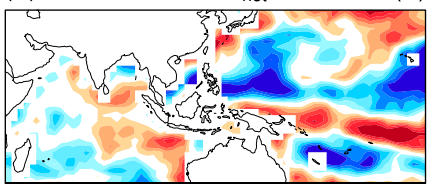

(e) Unstd ENSO Q

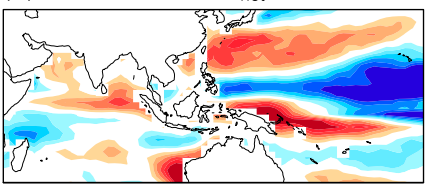

(h) Unstd ENSO $Q_{\text {net }}$ change

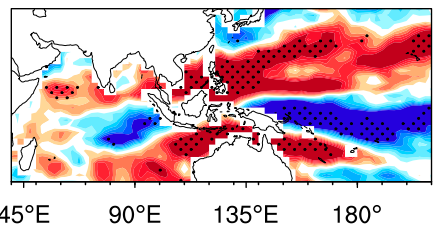

(c) Unstd ENSO Q $Q_{\text {net }} \quad$ JJA(1)

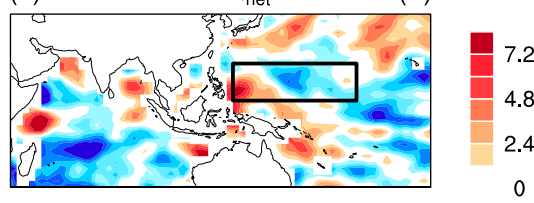

(f) Unstd ENSO $Q_{\text {net }}$

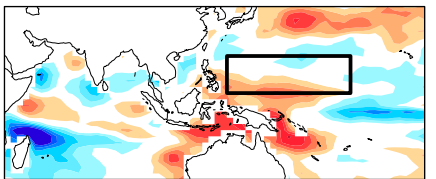

(i) Unstd ENSO $Q_{n e t}$ change

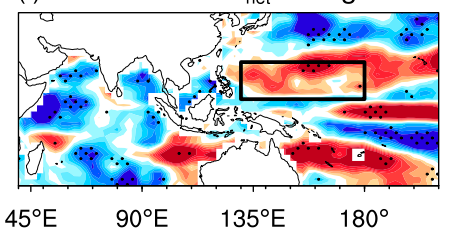

블

1.5

0

$=-1.5$

1

FIG. 9. Regressed anomalies of net surface heat flux anomalies (positive downward) from $\mathrm{D}(0) \mathrm{JF}(1)$ to $\mathrm{JJA}(1)$ on the $\mathrm{D}(0) \mathrm{JF}(1)$ unstandardized Niño-3.4 index in (a)-(c) observations and (d)-(f) the historical run for 1971-2000. (g)-(i) The corresponding ENSOinduced net surface heat flux anomalies changes in 2071-2100 relative to those in 1971-2000. The stippled region in (g)-(i) indicates where the sign of the MME projected change agrees in more than 13 models. The black boxes in (c),(f),(i) highlight the NWP region.

$\mathrm{D}(0) \mathrm{JF}(1)$ to $\mathrm{MAM}(1)$, and over the TIO and the tropical western Pacific in JJA(1), which is consistent with $\mathrm{Hu}$ et al. (2014). In a warmer world, the strengthened tropospheric temperature anomalies may enhance the warm TIO SST anomalies through moist convective

(a) Unstd ENSO TT

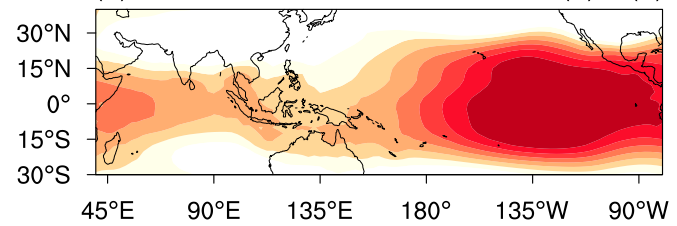

(b) Unstd ENSO TT

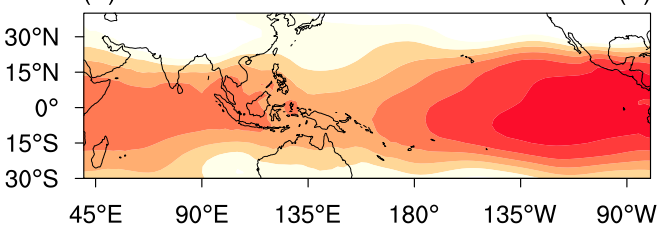

(c) Unstd ENSO TT

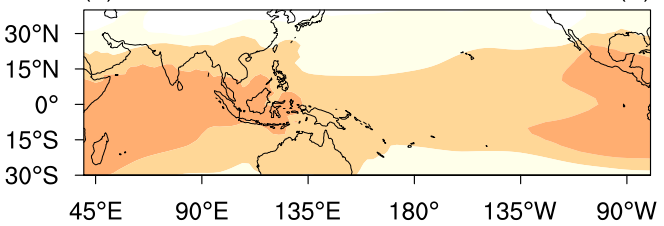

$\begin{array}{lllllll}0 & 0.1 & 0.2 & 0.3 & 0.4 & 0.5 & 0.6\end{array}$ processes, especially in the south Indian Ocean and the east coast of North Africa.

In the southwestern Indian Ocean (SWIO) at approximately $5^{\circ}-10^{\circ} \mathrm{S}, 50^{\circ}-80^{\circ} \mathrm{E}$, where the thermocline is shallow, the warm SWIO SST anomalies can be attributed

FIG. 10. As in Fig. 8, but for the tropospheric (1000-200 hPa) temperature anomalies.

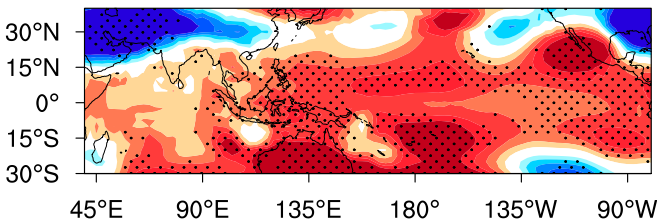

(e) Unstd ENSO TT change

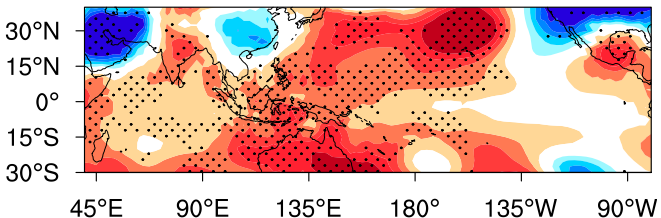

(f) Unstd ENSO TT change
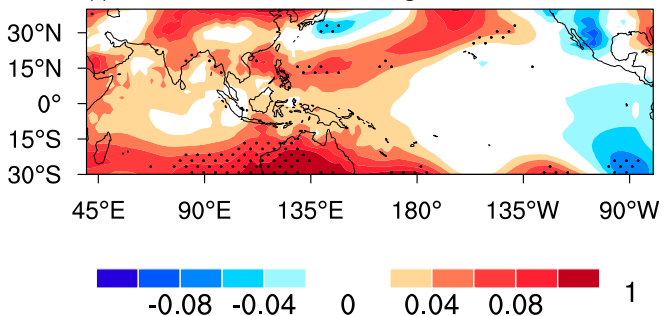
to ocean dynamical processes (Huang and Kinter 2002; Xie et al. 2002). An anomalous anticyclone appears over the southeastern Indian Ocean during the El Niño mature winter (Fig. 7a), which can force a westwardpropagating downwelling Rossby wave. The Rossby wave propagates westward to the SWIO, and then raises the SST in the SWIO by deepening the thermocline (Xie et al. 2002). However, the anomalous anticyclone over the southeastern Indian Ocean is weakened by the weakening of the atmospheric circulation in response to ENSO under global warming in the El Niño mature phase (Fig. 7d). This can alleviate the warming in the tropical SWIO by abating the oceanic Rossby wave in the following spring and summer.

The anomalous SWIO warming is important to the antisymmetric wind pattern, which intensifies local convection and induces a cross-equatorial SST gradient, leading to the antisymmetric wind pattern. The antisymmetric wind pattern plays an important role in triggering the second warming in the NIO through the WES feedback during post-El Niño summers (Du et al. 2009). Specifically, the anomalous easterlies over the NIO reduce the prevailing southwest monsoon and warm the ocean, generating the second warming in the NIO. Under global warming, however, the anomalous easterlies over the NIO are significantly decelerated during postEl Niño summers (Fig. 7f), which may be attributable to the unstrengthened warming changes in the region $5^{\circ}-10^{\circ} \mathrm{S}, 50^{\circ}-80^{\circ} \mathrm{E}$ of the SWIO and the significant warming changes of NWP SST anomalies (Fig. 5e). The slackened anomalous easterlies can strengthen the surface wind speed over the NIO and enhance evaporation (Fig. 8f), cooling the NIO SST anomalies (Fig. 5f).

In general, the decreased surface heat flux anomalies contribute to weaken the warm SST anomalies in most regions of the TIO. However, the strengthened tropospheric temperature anomalies play an important role in enhancing the warm TIO SST anomalies. In addition, the anomalous anticyclone over the southeastern Indian Ocean decreases under global warming, which is not conducive to the warming of the SWIO SST anomalies. Some studies found that the thermocline in the SWIO deepens in some models under global warming (Xie et al. 2010a; Zheng et al. 2013, 2016), which may weaken the effect of ocean dynamics on the SWIO SST anomalies. Thus, there is no significant change in the SWIO SST anomalies. The slackened anomalous easterlies over the NIO, because of the unstrengthened SWIO SST anomalies and the significant warming changes of the NWP SST anomalies, play an important role in cooling the NIO SST anomalies. These different processes offset each other, resulting in an undistinctive change of the SST anomalies in most regions of the TIO in the MME. Although the changes in the TIO SST anomalies show a large spread among the models, it does not change the robust weakening of the SST anomaly gradient between the TIO and the NWP.

\section{Summary}

In this work, we investigate the changes in the NWPAC in response to El Niño during post-El Niño summers under global warming using the historical and RCP8.5 runs of CMIP5 simulations, which will be important for further research on the impact of ENSO on the summer climate in East Asia. Our results show that the NWPAC during post-El Niño summers is likely weakened under global warming based on 18 selected models, potentially caused by the change in the SST evolution associated with ENSO. Under a warmer climate, the NWP SST anomalies are potentially weakened from the El Niño mature winter to the following summer, whereas the TIO SST anomalies show an undistinctive change. As a result, the robust decreased gradient of SST anomalies between the TIO and the NWP favors a weakening of the NWPAC during postEl Niño summers.

The possible mechanisms for the response of the NWP and TIO SST anomalies to ENSO are examined. The weakening of the atmospheric circulation in response to ENSO may play a crucial role in the weakening of the NWPAC in the El Niño mature winter (Huang et al. 2017). The weakened warm SST anomalies in the equatorial central-eastern Pacific in the following spring may also facilitate the MAM(1) weakening of the NWPAC (Wu et al. 2017). The resulting weakened local air-sea interaction during the following spring and summer contributes to the weakened SST anomalies in the NWP. Moreover, the increased net surface heat flux anomalies also contribute to the weakened cold NWP SST anomalies.

For the Indian Ocean, the weakening of the $\mathrm{D}(0) \mathrm{JF}(1)$ anomalous anticyclone over the southeastern Indian Ocean does not favor the warm SWIO SST anomalies. However, the tropospheric temperature anomalies are clearly strengthened over the TIO (Hu et al. 2014), which may enhance the warm TIO SST anomalies. Moreover, the significant warming of the NWP SST anomalies with almost unchanged anomalous SWIO warming can give rise to a slackening of the anomalous easterlies over the NIO, cooling the NIO SST by enhancing evaporation. The decreased net surface heat flux anomalies over the TIO contribute to the weakened warm TIO SST anomalies. Because of the multiple conflicting processes, the SST anomalies in most regions of the TIO are not robust among the models.

With the slight change of the TIO SST anomalies, the robust weakening of the SST anomalies in the NWP 
induces a strong weakened SST gradient between the TIO and the NWP. In turn, the decreased zonal contrast between the anomalous TIO warming and anomalous NWP cooling can further weaken the anomalous NWPAC because of the positive feedback between the changes to the SST anomalies and the NWPAC (Xie et al. 2016). As a result, the weakening of the NWPAC in response to El Niño during post-El Niño summers becomes more significant as global warming intensifies.

\section{Discussion}

In the present study, the results are based on the MME of the 18 selected CMIP5 CGCMs. Although the 18 selected models are high-skill models in simulating the ENSO-NWPSM relationship, there are apparent discrepancies between the observed and simulated ENSO-NWPSM relationships in the selected models and intermodel uncertainties, such as the JJA(1) change in TIO SST anomalies and the tropospheric temperature anomalies over the TIO. Further research is necessary to assess the intermodel uncertainty of ENSO-NWPSM teleconnection changes. In addition, the present study just emphasizes the effect of the atmospheric adjustment on the SST anomaly changes in the NWP and the TIO. Some other factors not considered, such as the oceanic dynamics in the southwestern TIO and the possible changes in the frequency of ENSO, could also contribute to the changes in the NWPAC anomalies.

The present study shows the weakening changes in NWPAC anomalies in post-El Niño summers are significant in the RCP8.5 run of 18 high-skill CMIP5 models, whether or not we consider the ENSO amplitude change in the future. These results seem contradictory with some previous studies, suggesting that NWPAC anomalies in response to El Niño tend to strengthen under global warming (Zheng et al. 2011; Chen et al. 2016). Comparing these results, we suspect that the discrepancy could be associated with different models, methods, and scenarios. For example, the enhanced NWPAC anomalies under global warming emphasized in Chen et al. (2016) are concluded for the short decaying El Niño events using nine best models in RCP4.5 runs. Actually, different El Niño decaying paces have diverse effects on Indian Ocean Basin warming (Li et al. 2012) and summer climate in the NWP and India (Chen et al. 2012; Chowdary et al. 2017); a short decaying El Niño leads to a strong NWPAC anomaly in the following summer, while the NWPAC anomaly often disappears during a long decaying El Niño (Chen et al. 2012). Chen et al. (2016) also indicated that the frequency of the long decaying El Niño is slightly increased in the RCP4.5 run, and the NWPAC anomalies in response to the long decaying El Niño events under global warming tend to be weakened. Thus, some different conclusions could be drawn when the RCP8.5 run results are used and the short and long decaying El Niños are considered together. In another study, Zheng et al. (2011) also obtained discrepant results using the outputs of a coupled model from the GFDL CM2.1 and performed the warming experiment under the Special Report on Emissions Scenarios A1B with a 720-ppm $\mathrm{CO}_{2}$ stabilization. Different selected models and different greenhouse gas emission scenarios may result in different conclusions. The influence of the model and scenario uncertainty would be investigated in future studies.

Acknowledgments. We thank the anonymous reviewers and Dr. Wei Chen for their valuable suggestions that helped us to improve the manuscript. This work was supported by the National Basic Research Program of China (2014CB953904), the National Natural Science Foundation of China (Grants 41425019, 41722504, and 41661144016), the Public Science and Technology Research Funds Projects of Ocean (201505013), and the Youth Innovation Promotion Association of CAS. We acknowledge the World Climate Research Programme's Working Group on Coupled Modelling, which is responsible for CMIP, and we thank the climate modeling groups listed in Table 1 for producing and making available their model output. For CMIP, the U.S. Department of Energy's Program for Climate Model Diagnosis and Intercomparison provides coordinating support and leads the development of software infrastructure in partnership with the Global Organization for Earth System Science Portals.

\section{REFERENCES}

Bonfils, C. J. W., B. D. Santer, T. J. Phillips, K. Marvel, L. R. Leung, C. Doutriaux, and A. Capotondi, 2015: Relative contributions of mean-state shifts and ENSO-driven variability to precipitation changes in a warming climate. J. Climate, 28, 999710013 , https://doi.org/10.1175/JCLI-D-15-0341.1.

Cai, W., and Coauthors, 2014: Increasing frequency of extreme El Niño events due to greenhouse warming. Nat. Climate Change, 4, 111-116, https://doi.org/10.1038/nclimate2100.

Chang, C.-P., Y. S. Zhang, and T. Li, 2000: Interannual and interdecadal variations of the East Asian summer monsoon and tropical Pacific SSTs. Part I: Roles of the subtropical ridge. J. Climate, 13, 4310-4325, https://doi.org/10.1175/1520-0442 (2000)013<4310:IAIVOT>2.0.CO;2.

Chen, W., J.-K. Park, B. Dong, R. Lu, and W.-S. Jung, 2012: The relationship between El Niño and the western North Pacific summer climate in a coupled GCM: Role of the transition of El Niño decaying phases. J. Geophys. Res., 117, D12111, https://doi.org/10.1029/2011JD017385.

, J.-Y. Lee, K.-J. Ha, K.-S. Yun, and R. Lu, 2016: Intensification of the western North Pacific anticyclone response to the short decaying El Niño event due to greenhouse 
warming. J. Climate, 29, 3607-3627, https://doi.org/10.1175/ JCLI-D-15-0195.1.

Chen, X. L., and T. J. Zhou, 2014: Relative role of tropical SST forcing in the 1990s periodicity change of the Pacific-Japan pattern interannual variability. J. Geophys. Res. Atmos., 119, 13 043-13 066, https://doi.org/10.1002/2014JD022064.

Chiang, J. C. H., and A. H. Sobel, 2002: Tropical tropospheric temperature variations caused by ENSO and their influence on the remote tropical climate. J. Climate, 15, 2616-2631, https://doi.org/ 10.1175/1520-0442(2002)015<2616:TTTVCB > 2.0.CO;2.

- and B. R. Lintner, 2005: Mechanisms of remote tropical surface warming during El Niño. J. Climate, 18, 4130-4149, https://doi.org/10.1175/JCLI3529.1.

Chou, C., J.-Y. Tu, and J.-Y. Yu, 2003: Interannual variability of the western North Pacific summer monsoon: Differences between ENSO and non-ENSO years. J. Climate, 16, 2275-2287, https://doi.org/10.1175/2761.1.

—, L.-F. Huang, J.-Y. Tu, L. S. Tseng, and Y.-C. Hsueh, 2009: El Niño impacts on precipitation in the western North PacificEast Asian sector. J. Climate, 22, 2039-2057, https://doi.org/ 10.1175/2008JCLI2649.1.

Chowdary, J. S., S.-P. Xie, H. Tokinaga, Y. M. Okumura, H. Kubota, N. Johnson, and X.-T. Zheng, 2012: Interdecadal variations in ENSO teleconnection to the Indo-western $\mathrm{Pa}$ cific for 1870-2007. J. Climate, 25, 1722-1744, https://doi.org/ 10.1175/JCLI-D-11-00070.1.

, H. S. Harsha, C. Gnanaseelan, G. Srinivas, A. Parekh, P. Pillai, and C. V. Naidu, 2017: Indian summer monsoon rainfall variability in response to differences in the decay phase of El Niño. Climate Dyn., 48, 2707-2727, https://doi.org/ 10.1007/s00382-016-3233-1.

Collins, M., and Coauthors, 2010: The impact of global warming on the tropical Pacific Ocean and El Niño. Nat. Geosci., 3, 391397, https://doi.org/10.1038/ngeo868.

Du, Y., and S.-P. Xie, 2008: Role of atmospheric adjustments in the tropical Indian Ocean warming during the 20th century in climate models. Geophys. Res. Lett., 35, L08712, https:// doi.org/10.1029/2008GL033631.

— - — - G. Huang, and K. Hu, 2009: Role of air-sea interaction in the long persistence of El Niño-induced north Indian Ocean warming. J. Climate, 22, 2023-2038, https://doi.org/10.1175/ 2008JCLI2590.1.

Feng, J., L. Wang, and W. Chen, 2014: How does the East Asian summer monsoon behave in the decaying phase of El Niño during different PDO phases? J. Climate, 27, 2682-2698, https://doi.org/10.1175/JCLI-D-13-00015.1.

Gill, A. E., 1980: Some simple solutions for heat-induced tropical circulation. Quart. J. Roy. Meteor. Soc., 106, 447-462, https:// doi.org/10.1002/qj.49710644905.

Ha, K.-J., J.-Y. Lee, B. Wang, S.-P. Xie, and A. Kitoh, 2017: Asian monsoon climate change-Understanding and prediction. Asia-Pac. J. Atmos. Sci., 53, 179-180, https://doi.org/10.1007/ s13143-017-0056-x.

Hu, K., G. Huang, X.-T. Zheng, S.-P. Xie, X. Qu, Y. Du, and L. Liu, 2014: Interdecadal variations in ENSO influences on northwest Pacific-East Asian early summertime climate simulated in CMIP5 models. J. Climate, 27, 5982-5998, https://doi.org/ 10.1175/JCLI-D-13-00268.1.

Huang, B. H., and J. L. Kinter III, 2002: Interannual variability in the tropical Indian Ocean. J. Geophys. Res., 107, 3199, https:// doi.org/10.1029/2001JC001278.

Huang, G., K. Hu, and S.-P. Xie, 2010: Strengthening of tropical Indian Ocean teleconnection to the northwest Pacific since the mid-1970s: An atmospheric GCM study. J. Climate, 23, 5294 5304, https://doi.org/10.1175/2010JCLI3577.1.

Huang, P., 2016: Time-varying response of ENSO-induced tropical Pacific rainfall to global warming in CMIP5 models. Part I: Multimodel ensemble results. J. Climate, 29, 5763-5778, https://doi.org/10.1175/JCLI-D-16-0058.1.

— , and S.-P. Xie, 2015: Mechanisms of change in ENSO-induced tropical Pacific rainfall variability in a warming climate. Nat. Geosci., 8, 922-926, https://doi.org/10.1038/ngeo2571.

- D. Chen, and J. Ying, 2017: Weakening of the tropical atmospheric circulation response to local sea surface temperature anomalies under global warming. J. Climate, 30, 8149-8158, https://doi.org/10.1175/JCLI-D-17-0171.1.

Huang, R., and Y. Wu, 1989: The influence of ENSO on the summer climate change in china and its mechanism. Adv. Atmos. Sci., 6, 21-32, https://doi.org/10.1007/BF02656915.

Jiang, W., G. Huang, K. Hu, R. Wu, H. Gong, X. Chen, and W. Tao, 2017: Diverse relationship between ENSO and the northwest Pacific summer climate among CMIP5 models: Dependence on the ENSO decay pace. J. Climate, 30, 109-127, https://doi.org/ 10.1175/JCLI-D-16-0365.1.

Kalnay, E., and Coauthors, 1996: The NCEP/NCAR 40-Year Reanalysis Project. Bull. Amer. Meteor. Soc., 77, 437-471, https://doi.org/10.1175/1520-0477(1996)077<0437: TNYRP $>2.0 . \mathrm{CO} ; 2$

Kim, S. T., W. Cai, F.-F. Jin, A. Santoso, L. Wu, E. Guilyardi, and S.-I. An, 2014: Response of El Niño sea surface temperature variability to greenhouse warming. Nat. Climate Change, $\mathbf{4}$, 786-790, https://doi.org/10.1038/nclimate2326.

Klein, S. A., B. J. Soden, and N.-C. Lau, 1999: Remote sea surface temperature variations during ENSO: Evidence for a tropical atmospheric bridge. J. Climate, 12, 917-932, https://doi.org/ 10.1175/1520-0442(1999)012<0917:RSSTVD>2.0.CO;2.

Kosaka, Y., S.-P. Xie, N.-C. Lau, and G. A. Vecchi, 2013: Origin of seasonal predictability for summer climate over the northwestern Pacific. Proc. Natl. Acad. Sci. USA, 110, 7574-7579, https://doi.org/10.1073/pnas.1215582110.

Kug, J.-S., S.-I. An, Y.-G. Ham, and I.-S. Kang, 2010: Changes in El Niño and La Niña teleconnections over North PacificAmerica in the global warming simulations. Theor. Appl. Climatol., 100, 275-282, https://doi.org/10.1007/s00704-009-0183-0.

Lau, N.-C., and M. J. Nath, 2000: Impact of ENSO on the variability of the Asian-Australian monsoons as simulated in GCM experiments. J. Climate, 13, 4287-4309, https://doi.org/ 10.1175/1520-0442(2000)013<4287:IOEOTV > 2.0.CO;2.

- , and - 2003: Atmosphere-ocean variations in the IndoPacific sector during ENSO episodes. J. Climate, 16, 3-20, https:// doi.org/10.1175/1520-0442(2003)016<0003:AOVITI>2.0.CO;2.

Li, Q., R.-C. Ren, M. Cai, and G. X. Wu, 2012: Attribution of the summer warming since 1970s in Indian Ocean basin to the inter-decadal change in the seasonal timing of El Niño decay phase. Geophys. Res. Lett., 39, L12702, https://doi.org/10.1029/ 2012GL052150.

Lin, Z. D., and R. Y. Lu, 2009: The ENSO's effect on eastern China rainfall in the following early summer. Adv. Atmos. Sci., 26, 333-342, https://doi.org/10.1007/s00376-009-0333-4.

Matsuno, T., 1966: Quasi-geostrophic motions in the equatorial area. J. Meteor. Soc. Japan, 44, 25-43, https://doi.org/10.2151/ jmsj1965.44.1_25.

Oh, H., and K.-J. Ha, 2016: Prediction of dominant intraseasonal modes in the East Asian-western North Pacific summer monsoon. Climate Dyn., 47, 2025-2037, https://doi.org/10.1007/ s00382-015-2948-8. 
Ohba, M., and H. Ueda, 2006: A role of zonal gradient of SST between the Indian Ocean and the western Pacific in localized convection around the Philippines. SOLA, 2, 176-179, https:// doi.org/10.2151/sola.2006-045.

Power, S. B., F. Delage, R. Colman, and A. Moise, 2012: Consensus on twenty-first-century rainfall projections in climate models more widespread than previously thought. J. Climate, 25, 3792-3809, https://doi.org/10.1175/JCLI-D-11-00354.1.

— - _ C C. Chung, G. Kociuba, and K. Keay, 2013: Robust twenty-first-century projections of El Niño and related precipitation variability. Nature, 502, 541-545, https://doi.org/ 10.1038/nature12580.

Smith, T. M., R. W. Reynolds, T. C. Peterson, and J. Lawrimore, 2008: Improvements to NOAA's historical merged landocean surface temperature analysis (1880-2006). J. Climate, 21, 2283-2296, https://doi.org/10.1175/2007JCLI2100.1.

Song, F., and T. Zhou, 2015: The crucial role of internal variability in modulating the decadal variation of the East Asian summer monsoon-ENSO relationship during the twentieth century. J. Climate, 28, 7093-7107, https://doi.org/10.1175/ JCLI-D-14-00783.1.

Stuecker, M. F., F.-F. Jin, A. Timmermann, and S. McGregor, 2015: Combination mode dynamics of the anomalous northwest Pacific anticyclone. J. Climate, 28, 1093-1111, https://doi.org/ 10.1175/JCLI-D-14-00225.1.

$\longrightarrow, \ldots,-$, and -2016 : Reply to "Comments on 'Combination mode dynamics of the anomalous northwest Pacific anticyclone."' J. Climate, 29, 4695-4706, https://doi.org/ 10.1175/JCLI-D-15-0558.1.

Taylor, K. E., R. J. Stouffer, and G. A. Meehl, 2012: An overview of CMIP5 and the experiment design. Bull. Amer. Meteor. Soc., 93, 485-498, https://doi.org/10.1175/BAMS-D-11-00094.1.

Terao, T., and T. Kubota, 2005: East-west SST contrast over the tropical oceans and the post El Niño western North Pacific summer monsoon. Geophys. Res. Lett., 32, L15706, https:// doi.org/10.1029/2005GL023010.

Wang, B., R. G. Wu, and X. H. Fu, 2000: Pacific-East Asian teleconnection: How does ENSO affect East Asian climate? J. Climate, 13, 1517-1536, https://doi.org/10.1175/1520-0442(2000)013<1517 PEATHD $>2.0 . \mathrm{CO} ; 2$.

_,- , and K. M. Lau, 2001: Interannual variability of the Asian summer monsoon: Contrasts between the Indian and the western North Pacific-East Asian monsoons. J. Climate, 14, 4073-4090, https://doi.org/10.1175/1520-0442(2001)014<4073:ivotas>2.0.co;2.

$\longrightarrow, \ldots$, and T. Li, 2003: Atmosphere-warm ocean interaction and its impacts on Asian-Australian monsoon variation. J. Climate, 16, 1195-1211, https://doi.org/10.1175/1520-0442(2003)16<1195: AOIAII $>2.0 . \mathrm{CO} ; 2$.

__ J. Yang, T. Zhou, and B. Wang, 2008: Interdecadal changes in the major modes of Asian-Australian monsoon variability: Strengthening relationship with ENSO since the late 1970s. J. Climate, 21,1771-1789, https://doi.org/10.1175/2007JCLI1981.1.

_ B. Q. Xiang, and J.-Y. Lee, 2013: Subtropical high predictability establishes a promising way for monsoon and tropical storm predictions. Proc. Natl. Acad. Sci. USA, 110, 2718-2722, https://doi.org/10.1073/pnas.1214626110.

Wu, B., T. Li, and T. Zhou, 2010: Relative contributions of the Indian Ocean and local SST anomalies to the maintenance of the western North Pacific anomalous anticyclone during the El Niño decaying summer. J. Climate, 23, 2974-2986, https:// doi.org/10.1175/2010JCLI3300.1.

- T. Zhou, and T. Li, 2017: Atmospheric dynamic and thermodynamic processes driving the western North Pacific anomalous anticyclone during El Niño. Part I: Maintenance mechanisms. J. Climate, 30, 9621-9635, https://doi.org/10.1175/ JCLI-D-16-0489.1.

Xiang, B., B. Wang, W. Yu, and S. Xu, 2013: How can anomalous western North Pacific subtropical high intensify in late summer? Geophys. Res. Lett., 40, 2349-2354, https://doi.org/10.1002/grl.50431.

Xie, S.-P., and S. G. H. Philander, 1994: A coupled oceanatmosphere model of relevance to the ITCZ in the eastern Pacific. Tellus, 46A, 340-350, https://doi.org/10.1034/ j.1600-0870.1994.t01-1-00001.x.

, and Z.-Q. Zhou, 2017: Seasonal modulations of El Niño-related atmospheric variability: Indo-western Pacific Ocean feedback. J. Climate, 30, 3461-3472, https://doi.org/10.1175/JCLI-D-16-0713.1. , H. Annamalai, F. A. Schott, and J. P. McCreary, 2002: Structure and mechanisms of south Indian Ocean climate variability. J. Climate, 15, 864-878, https://doi.org/10.1175/ 1520-0442(2002)015<0864:SAMOSI >2.0.CO;2.

— K. Ku, J. Hafner, H. Tokinaga, Y. Du, G. Huang, and T. Sampe, 2009: Indian Ocean capacitor effect on Indo-western Pacific climate during the summer following El Niño. J. Climate, 22, 730-747, https://doi.org/10.1175/2008JCLI2544.1.

, C. Deser, G. A. Vecchi, J. Ma, H. Teng, and A. T. Wittenberg, 2010a: Global warming pattern formation: Sea surface temperature and rainfall. J. Climate, 23, 966-986, https://doi.org/ 10.1175/2009JCLI3329.1.

—, Y. Du, G. Huang, X.-T. Zheng, H. Tokinaga, K. Hu, and Q. Liu, 2010b: Decadal shift in El Niño influences on Indowestern Pacific and East Asian climate in the 1970s. J. Climate, 23, 3352-3368, https://doi.org/10.1175/2010JCLI3429.1.

, Y. Kosaka, Y. Du, K. Hu, J. S. Chowdary, and G. Huang, 2016: Indo-western Pacific Ocean capacitor and coherent climate anomalies in post-ENSO summer: A review. Adv. Atmos. Sci., 33, 411-432, https://doi.org/10.1007/s00376-015-5192-6.

Yang, J. L., Q. Y. Liu, S.-P. Xie, Z. Y. Liu, and L. X. Wu, 2007: Impact of the Indian Ocean SST basin mode on the Asian summer monsoon. Geophys. Res. Lett., 34, L02708, https:// doi.org/10.1029/2006GL028571.

- — - and Z. Y. Liu, 2010: Linking observations of the Asian monsoon to the Indian Ocean SST: Possible roles of Indian Ocean Basin mode and dipole mode. J. Climate, 23, 58895902, https://doi.org/10.1175/2010JCLI2962.1.

Zhang, R. H., and A. Sumi, 2002: Moisture circulation over East Asia during El Niño episode in northern winter, spring and autumn. J. Meteor. Soc. Japan, 80, 213-227, https://doi.org/ $10.2151 /$ jmsj. 80.213

, and M. Kimoto, 1999: A diagnostic study of the impact of El Niño on the precipitation in China. Adv. Atmos. Sci., 16, 229-241, https://doi.org/10.1007/BF02973084.

Zheng, X.-T., S.-P. Xie, and Q. Liu, 2011: Response of the Indian Ocean Basin mode and its capacitor effect to global warming. J. Climate, 24, 6146-6164, https://doi.org/10.1175/2011JCLI4169.1.

,$- \ldots$, Y. Du, L. Liu, G. Huang, and Q. Liu, 2013: Indian Ocean dipole response to global warming in the CMIP5 multimodel ensemble. J. Climate, 26, 6067-6080, https:// doi.org/10.1175/JCLI-D-12-00638.1.

, L. Gao, G. Li, and Y. Du, 2016: The southwest Indian Ocean thermocline dome in CMIP5 models: Historical simulation and future projection. Adv. Atmos. Sci., 33, 489-503, https:// doi.org/10.1007/s00376-015-5076-9.

Zhou, Z.-Q., S.-P. Xie, X.-T. Zheng, Q. Liu, and H. Wang, 2014: Global warming-induced changes in El Niño teleconnections over the North Pacific and North America. J. Climate, 27, 9050-9064, https://doi.org/10.1175/JCLI-D-14-00254.1. 